\title{
The resolution sensitivity of the South Asian monsoon and Indo-Pacific in a global $0.35^{\circ} \mathrm{AGCM}$
}

\author{
Stephanie J. Johnson ${ }^{1} \cdot$ Richard C. Levine $^{2} \cdot$ Andrew G. Turner $^{1} \cdot$ Gill M. Martin $^{2}$ • \\ Steven J. Woolnough ${ }^{1} \cdot$ Reinhard Schiemann $^{1} \cdot$ Matthew S. Mizielinski $^{2}$. \\ Malcolm J. Roberts ${ }^{2} \cdot$ Pier Luigi Vidale ${ }^{1} \cdot$ Marie-Estelle Demory $^{1} \cdot$ Jane Strachan $^{2}$
}

Received: 11 September 2014 / Accepted: 10 April 2015 / Published online: 22 May 2015

(C) The Author(s) 2015. This article is published with open access at Springerlink.com

\begin{abstract}
The South Asian monsoon is one of the most significant manifestations of the seasonal cycle. It directly impacts nearly one third of the world's population and also has substantial global influence. Using 27-year integrations of a high-resolution atmospheric general circulation model (Met Office Unified Model), we study changes in South Asian monsoon precipitation and circulation when horizontal resolution is increased from approximately $200-40 \mathrm{~km}$ at the equator (N96-N512, $1.9^{\circ}-0.35^{\circ}$ ). The high resolution, integration length and ensemble size of the dataset make this the most extensive dataset used to evaluate the resolution sensitivity of the South Asian monsoon to date. We find a consistent pattern of JJAS precipitation and circulation changes as resolution increases, which include a slight increase in precipitation over peninsular India, changes in Indian and Indochinese orographic rain bands, increasing wind speeds in the Somali Jet, increasing precipitation over the Maritime Continent islands and decreasing precipitation over the northern Maritime Continent seas. To diagnose which resolution-related processes cause these changes, we compare them to published sensitivity experiments that change regional orography and coastlines. Our analysis indicates that improved resolution of the East African Highlands results in the improved representation of the Somali Jet and further suggests that improved resolution of orography over Indochina
\end{abstract}

Stephanie J. Johnson was previously known as Stephanie J. Bush.

Stephanie J. Johnson

s.j.bush@reading.ac.uk

1 National Centre for Atmospheric Science - Climate Directorate, Department of Meteorology, University of Reading, Earley Gate, Reading RG6 6BB, UK

2 Met Office Hadley Centre, FitzRoy Road, Exeter EX1 3PB, UK and the Maritime Continent results in more precipitation over the Maritime Continent islands at the expense of reduced precipitation further north. We also evaluate the resolution sensitivity of monsoon depressions and lows, which contribute more precipitation over northeast India at higher resolution. We conclude that while increasing resolution at these scales does not solve the many monsoon biases that exist in GCMs, it has a number of small, beneficial impacts.

Keywords Asian monsoon - Maritime Continent · Orography $\cdot$ High resolution · African highlands · Monsoon depressions

\section{Introduction}

In global circulation model (GCM) assessments such as the third and fifth Coupled Model Intercomparison Projects (CMIP3 and CMIP5, Meehl et al. 2007; Taylor et al. 2012) large biases remain in the simulation of important climate systems such as the South Asian monsoon (Sperber et al. 2013). These biases span many temporal and spatial scales and are observed in coupled and atmosphere-only GCMs (Gadgil and Sajani 1998; Annamalai et al. 2007; Randall et al. 2007; Sperber et al. 2013). Biases in simulated seasonal mean monsoon precipitation include excess precipitation over the equatorial Indian Ocean, low precipitation over the Indian subcontinent and excess precipitation over orography such as the southern slopes of the Himalayas (Sperber and Palmer 1996; Gadgil and Sajani 1998; Annamalai et al. 2007; Bollasina and Nigam 2009; Sperber et al. 2013). GCMs' simulated monsoon onsets are typically too late (Sperber et al. 2013) and the boreal summer intraseasonal oscillation (BSISO), which has a particularly large socio-economic impact in South Asia, is often weak or not 
Table 1 Some previous studies of the Asian monsoon's resolution sensitivity in atmosphere only models

\begin{tabular}{|c|c|c|c|c|c|c|}
\hline GCM & Resolution & $\begin{array}{l}\text { Resolution at } \\
\text { equator }(\mathrm{km})\end{array}$ & $\begin{array}{l}\text { Integration } \\
\text { length }\end{array}$ & $\begin{array}{l}\text { Ensemble } \\
\text { members }\end{array}$ & SSTs & References \\
\hline MetUM & N96-N512 & $208-39$ & 27 years & $3-5$ & AMIP-style & This study \\
\hline LMD & Variable resolution mesh & $\sim 35$ & 1 year & 10 & Climatological & Sabin et al. (2013) \\
\hline JMA & $\mathrm{T}_{L} 95(\mathrm{~T} 63)-\mathrm{T}_{L} 959$ & $317-32$ & 20 years & $1-3$ & AMIP-style & $\begin{array}{l}\text { Kitoh and Kusunoki } \\
\text { (2008) }\end{array}$ \\
\hline JMA & $\mathrm{T} 42-\mathrm{T} 213$ & $476-94$ & 3 years & 1 & Climatological & $\begin{array}{l}\text { Kitoh and Kusunoki } \\
\text { (2004) }\end{array}$ \\
\hline FSU & $\mathrm{T} 42-\mathrm{T} 120$ & $476-166$ & 1 month & 1 & AMIP-style & Jha et al. (2000) \\
\hline MetUM & N48-N144 & $417-138$ & 10 years & 1 & AMIP-style & Martin (1999) \\
\hline ARPEGE & $\mathrm{T} 21-\mathrm{T} 63$ & $953-317$ & 4 years & 1 & AMIP-style & Stephenson et al. (1998) \\
\hline IFS & $\mathrm{T} 21-\mathrm{T} 106$ & $953-189$ & 1 year & 1 & Climatological & Sperber et al. (1994) \\
\hline
\end{tabular}

The resolution, integration length, number of ensemble members and type of SSTs (climatological or annually varying, denoted AMIP-style) are listed. Some of the AMIP-style SSTs are monthly averaged while others are averaged over shorter time scales. The GCM column indicates the GCM name, but not the version of that GCM. For example, the version of the MetUM used by Martin (1999) differs considerably from that used here

present (e.g. Sabeerali et al. 2013; Sperber et al. 2013). Monsoon low pressure systems (LPS), including the more intense monsoon depressions and less intense monsoon lows, are synoptic systems that generally develop in the Bay of Bengal and pass up the monsoon trough, increasing precipitation in central and northern India and generating many of the most intense rain events in the monsoon (Sikka 1977; Krishnamurthy and Misra 2010). These systems are often too infrequent and too weak in GCMs (Ashok et al. 2000; Sabre et al. 2000; Stowasser et al. 2009).

Most of these biases improve slightly in CMIP5 GCMs compared to CMIP3 GCMs. CMIP5 GCMs typically have higher horizontal and vertical resolution in the atmosphere and ocean than CMIP3 GCMs and usually include parametrisations of more physical processes, such as a more detailed treatment of aerosols and a more complete representation of the carbon cycle (Sperber et al. 2013). Since the CMIP samples are composed of many diverse GCMs, it is difficult to attribute the monsoon improvement to any particular physics or resolution change in the atmosphere or ocean components.

Here, we evaluate how the simulated Asian monsoon responds to increasing horizontal atmospheric resolution from approximately 200 to $40 \mathrm{~km}$ in atmosphereonly climate integrations of the Met Office Unified Model (MetUM, Sect. 2.2). Previous studies which used different GCMs, integration lengths, and different initial resolutions have also analysed the South Asian monsoon's sensitivity to increased resolution in atmosphere-only GCMs (AGCMs). The studies are summarised in Table 1. We expect some differences between their findings depending on the GCM used, for example, the amplitude and sign of seasonal mean precipitation resolution sensitivity depends on the choice of convection scheme (Shin et al. 2003). We also expect the response to depend on how the studies' the initial resolution, and resolution increase, compare to the scales of features and processes relevant to the monsoon, such as specific orographic features or synoptic scale variability.

Despite the expected variation, similarities in the resolution sensitivity exist throughout these studies. Improvements in the spatial distribution of orographic precipitation windward of the Western Ghats and the Indochina peninsula is common (Jha et al. 2000; Kitoh and Kusunoki 2004). The lower tropospheric monsoon circulation, such as the peak wind speed of the Somali Jet, generally improves with increasing resolution (Sperber et al. 1994; Sabin et al. 2013). Some studies have also shown increased easterlies extending further along the monsoon trough just south of the Himalayas (Sabin et al. 2013). In contrast, the western equatorial Indian Ocean (WEIO, Sperber et al. 1994; Sabin et al. 2013) and Indian peninsula (Sperber et al. 1994; Stephenson et al. 1998; Martin 1999; Sabin et al. 2013) are key monsoon regions in which the resolution sensitivity of the precipitation is inconsistent across studies in both sign and magnitude.

In this study, we analyse multiple 27-year MetUM AMIP-style climate integrations ranging from approximately 200-40 km horizontal resolution (N96-N512) generated for the UK on PRACE: weather resolving Simulations of Climate for globAL Environmental risk campaign (UPSCALE campaign, Mizielinski et al. 2014). As many other aspects of the GCM as possible remain unchanged, which allows us to directly attribute changes in precipitation and circulation to the resolution increase and to analyse where and how increasing resolution has the most impact on the monsoon. Due to the length of the integrations and number of ensemble members, this dataset is more extensive than any other individual GCM dataset used to study the sensitivity of the South Asian 
monsoon to horizontal resolution. Using this resource, we analyse the resolution dependence of the JJAS mean state in the tropical Indo-Pacific, the monsoon seasonal cycle, monsoon variability and monsoon LPS. We focus on understanding which resolution-related processes cause the sensitivity and explore changes in processes across the Indo-Pacific warm pool that may affect the South Asian monsoon.

There are many possible drivers of this resolution sensitivity. Improving the resolution might be expected to improve the representation of high temporal variability events which are responsible for much of the extreme precipitation in South Asia. For example, numbers of tropical cyclones and monsoon LPS in the Indian Ocean increase with resolution in some GCMs (Kitoh and Kusunoki 2004; Sabin et al. 2013). Another important source of resolution sensitivity is the representation of orography. Several orographic features are fundamental drivers of the South Asian monsoon through multiple mechanisms: orographically forced precipitation and the resulting diabatic heating (Xie et al. 2006), providing a barrier between extratropical and tropical air (Boos and Kuang 2010, 2013; Tang et al. 2013), elevated surface heating (e.g. Li and Yanai 1996) and confinement and modification of the cross-equatorial monsoon circulation (Hoskins and Rodwell 1995; Rodwell and Hoskins 1995; Slingo et al. 2005). As horizontal resolution increases, more of the orography is resolved, and the contribution from the orographic parameterisation should reduce, which may change the overall impact of orography in the GCM. The representation of islands and coastlines is also important in the South Asian monsoon domain. As a collection of many islands at or below the typical grid-scale of GCMs, the Maritime Continent is a difficult test for parameterisations and large precipitation biases have existed over the Maritime Continent in many versions of the MetUM (Neale and Slingo 2003; Strachan 2007; Schiemann et al. 2014). As a large error in diabatic forcing in the monsoon domain, any resolution sensitivity of Maritime Continent biases may affect the precipitation and circulation over India through alteration of the Walker circulation or wave activity (Neale and Slingo 2003). We consequently include the Maritime Continent in the South Asian monsoon domain we study here.

In Sect. 2 we describe the configuration of the MetUM used in this study and our experimental design. In Sect. 3 we present diagnostics of many aspects of the monsoon and discuss their resolution sensitivity. In Sect. 4 we investigate the sources of the largest changes found in Sect. 3 . In Sect. 5 we combine our findings into a coherent picture of the resolution sensitivity in the South Asian monsoon domain and discuss the implications. In Sect. 6, we summarise our findings.

\section{Methodology}

\subsection{Experimental design}

The UPSCALE dataset (Mizielinski et al. 2014) consists of multiple ensemble members of AMIP-style climate model integrations at N96, N216, N512 resolution with 85 vertical levels extending to $85 \mathrm{~km}$. Integrations were conducted for present and future climate conditions. We analyse the present climate integrations in this study, which run from February 1985 to December 2011. The five N512 ensemble members were initialised with conditions taken from consecutive days of a 5-year N512 spin-up run, which was initialised with conditions from an $\mathrm{N} 320(\approx 62 \mathrm{~km})$ integration from the MetUM model development programme. Three ensemble members at N216 and five ensemble members at N96 were initialised from the N512 initial conditions interpolated to lower resolution. The integrations are summarised in Table 1 and the model configuration is described in Sect. 2.2.

\subsection{MetUM configuration}

UPSCALE used a version of the Global Atmosphere 3.0 (GA3.0, Walters et al. 2011) configuration of the atmospheric component of the HadGEM3 family of models, which we will refer to as the Met Office Unified Model (MetUM). The model configuration is a unique choice of atmospheric MetUM dynamical core, atmospheric parameterisations, settings and forcings. The default GA3 configuration is described in Walters et al. (2011). Very few scientific settings in the MetUM are changed with resolution, but a few parameters must be changed to ensure numerical stability. An example is the dynamical core's alternatingdirection implicit (ADI) pseudo time-step (Davies et al. 2005), which is related to the efficiency of the implicit solver at high latitudes. The parameters changed with resolution, or changed from their default settings to apply at all resolutions, are listed in Table 2. In addition to these alterations, diffusion is applied to vertical wind velocities in the upper five levels of the atmosphere to dissipate grid-scale artifacts in the stratosphere (Mizielinski et al. 2014). Here, we summarise the aspects of the MetUM that are relevant to horizontal resolution sensitivity in the South Asian monsoon domain. Further details can be found in Walters et al. (2011).

\subsubsection{Prescribed sea surface temperatures}

UPSCALE prescribes daily sea surface temperature (SST) and sea-ice forcings bilinearly interpolated to the MetUM grids from the OSTIA product, which combines satellite and in-situ observation into a product with a native resolution of one-twentieth degree (Donlon et al. 2012). The 
Table 2 MetUM configurations used in this study

\begin{tabular}{llll}
\hline Parameter & $\mathrm{N} 96$ & $\mathrm{~N} 216$ & $\mathrm{~N} 512$ \\
\hline $\mathrm{N}_{x} \times \mathrm{N}_{y}$ & $192 \times 145$ & $432 \times 325$ & $1024 \times 769$ \\
Lon $\times$ lat $\left(^{\circ}\right)$ & $1.875 \times 1.245$ & $0.83 \times 0.55$ & $0.35 \times 0.23$ \\
Lon $\times$ lat (at equator, $\mathrm{km})$ & $208 \times 139$ & $93 \times 62$ & $39 \times 26$ \\
Time step (min) & 20 & 15 & 10 \\
ADI pseudo time step & $8 \times 10^{-4}$ & $3 \times 10^{-4}$ & $10^{-4}$ \\
Targeted diffusion W threshold $\left(\mathrm{m} \mathrm{s}^{-1}\right)$ & 0.5 & 1.0 & 1.0 \\
CAPE closure time scale (s) & 3600 & 3600 & 3600 \\
Threshold W for reduction of CAPE time scale $\left(\mathrm{m} \mathrm{s}^{-1}\right)$ & 0.4 & 0.4 & 0.4 \\
\hline
\end{tabular}

The resolution naming convention number, $\mathrm{N}$, defines the resolution of the configuration grid, which has $2 \mathrm{~N}$ longitude and $1.5 \mathrm{~N}+1$ latitude grid-points
JJAS mean prescribed SSTs in the Indo-Pacific warm pool region are shown in the bottom panels of Fig. 1. While the SST distribution changes little with resolution, smaller features, such as the variation in SST around the islands of the Maritime Continent, are resolved at higher resolution.

\subsubsection{Land surface model and coastal tiling scheme}

The land surface fluxes are calculated with the community land surface model Joint UK Land Environment Simulator GL 3.0 (JULES, Best et al. 2011; Clark et al. 2011; Walters et al. 2011). The $2^{\prime}$ Gridded Global Relief Data (ETOPO2, US Department of Commerce 2001) dataset is degraded to $1^{\circ}$ (N96) or $0.25^{\circ}$ (N216 and N512) and used to designate land and sea grid-points. Atmospheric grid-points that have both land and sea in them (including sub-grid islands) are designated coastal grid points and assigned a land fraction. The land fraction boundary conditions are shown in the middle panels of Fig. 1. Red regions are land gridpoints, white regions are sea grid-points and other colours indicate coastal grid-points. At higher resolution the fraction of coastal points decreases markedly, while the fraction of land and sea points increases, particularly over the Maritime Continent and around the Arabian Peninsula. Due to the different course-graining of the N96 and higher resolution configurations, fewer islands appear in the West Pacific in the N96 configuration, than in higher resolution configurations.

Coastal surface fluxes are computed separately for the land and sea fractions of each grid point, then passed to the atmosphere such that the total flux is accounted for. This coastal tiling scheme blurs the coastline over a grid box. Consequently, the apparent width of coastlines decreases as resolution increases (Johns et al. 2006). In the MetUM configuration used here, a "buddy" scheme is added to the coastal tiling scheme, which splits the lowest level atmospheric wind speeds over coastal points into separate land and sea contributions using the average wind speed over sea grid points adjacent to a coastal grid point. This increases the wind speed over the sea part of the grid-box, improving the scalar surface fluxes (Walters et al. 2011).

\subsubsection{MetUM response to orography}

The MetUM dynamical core uses a semi-implicit, semiLagrangian formulation to solve the non-hydrostatic, fully compressible deep atmosphere equations of motion (Davies et al. 2005) using prognostic fields discretised horizontally on the Arakawa-C grid (Arakawa and Lamb 1977) and vertically on terrain-following hybrid height levels using Charney-Phillips staggering (Charney and Phillips 1953). On the grid-scale, the MetUM dynamical core responds to the mean height of orography in a grid-box derived from the GloBal One-km Base Elevation dataset (GLOBE, GLOBE Task Team 1999), which has a native resolution of $30^{\prime \prime}$. The grid-scale orographic boundary condition is shown in Fig. 1. As resolution increases, orographic height increases in many locations. Examples include the East African Highlands in Ethiopia and along the horn of Africa, and the New Guinea Highlands on the Maritime Continent. The effects of orographic features smaller than the gridscale are parametrised.

As described in Walters et al. (2011), there are three parameterisations that represent different effects of the subgrid orography: boundary layer drag, flow blocking and gravity wave drag. On the smallest scales, the momentum used by the boundary layer scheme is adjusted through an increased roughness length over orography (Gregory et al. 1998). On larger scales, where buoyancy effects are important, the sub-grid orography is represented by a measure of amplitude, which is proportional to the standard deviation

Fig. 1 Fixed boundary conditions for the N96, N216 and N512 atmosphere-only configurations of the MetUM. Top Grid-point mean orographic height $(\mathrm{km})$. Middle Grid-point land fraction. Red indicates a land fraction of one which is a land grid-point, while white indicates a land fraction of zero which is a sea grid-point. Other colours indicate the land fraction of coastal grid-points. Bottom JJAS mean SST $\left({ }^{\circ} \mathrm{C}\right)$ 


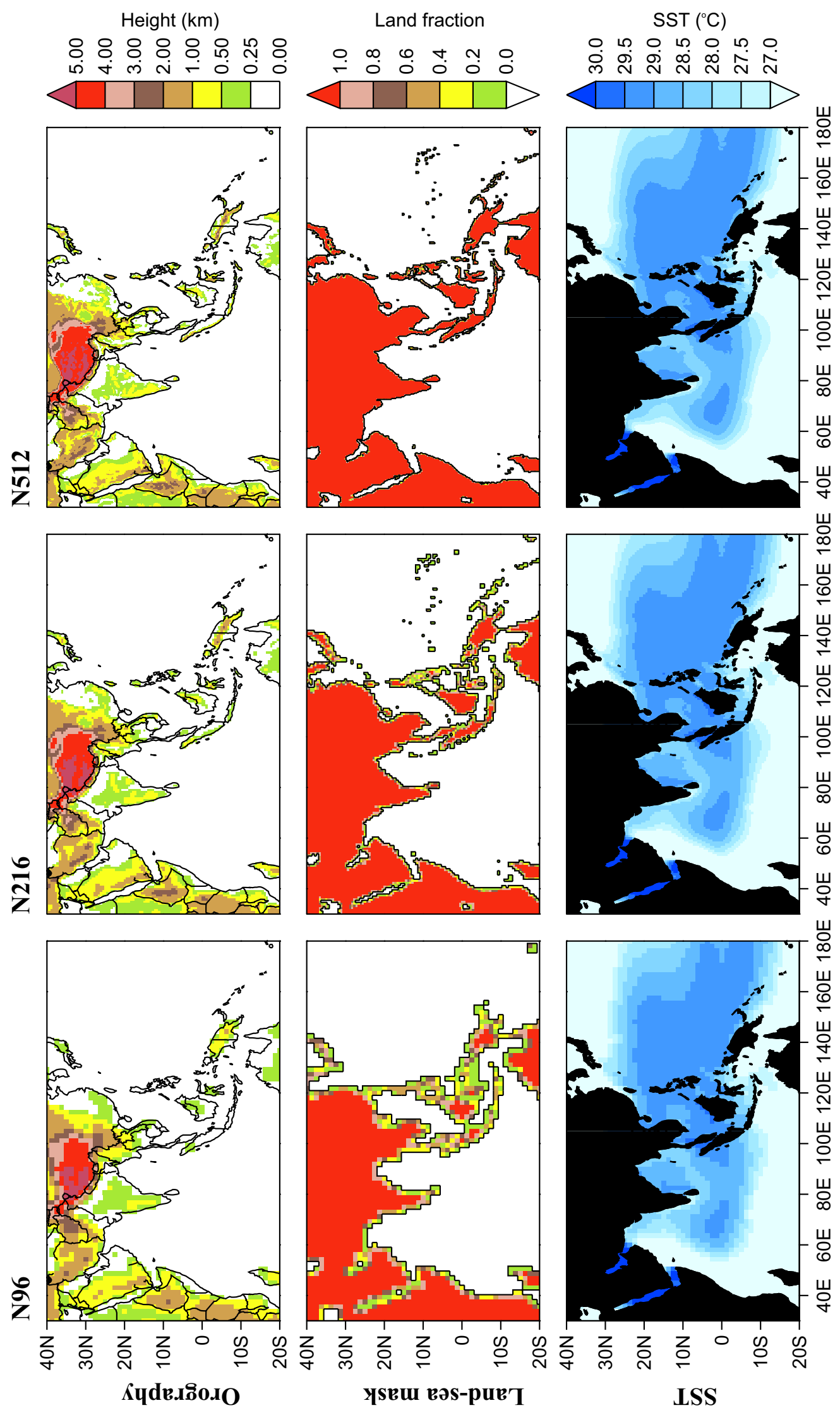


of the source orography in a model grid-box, and a measure of anisotropy. The total surface stress from orography is determined using a simple linear hydrostatic expression, which is proportional to the bulk lower level winds and atmospheric stability. The total stress is then partitioned into a gravity wave component representing flow over the sub-grid orography and a flow blocking component representing flow around the sub-grid orography. Flow blocking drag is exerted over the depth of the sub-grid orography assuming a linear decrease with height, while the gravity wave drag is exerted at levels where wave breaking and wave saturation are diagnosed. The drag is applied as increments to the MetUM wind fields, and a numerical limiter is imposed on flow blocking drag to ensure numerical stability (Brown and Webster 2004). As horizontal resolution is increased, more orography is resolved explicitly, and less is parametrised.

\subsubsection{Convective parametrisation}

As the South Asian monsoon is dominated by convective precipitation, it is very sensitive to MetUM parameters relating to convection. Convective parametrisation in the MetUM is derived from the bulk mass flux scheme developed by Gregory and Rowntree (1990). The scheme's foundation is single plume parcel theory modified to represent the average properties of an ensemble of convective plumes. The scheme triggers convection from the boundary layer using an undilute parcel calculation, then performs shallow or deep convection for grid points where convection is triggered. Mid-level convection can be triggered from levels in the free troposphere.

Deep convective precipitation dominates in the tropical Indo-Pacific region. Several adjustments to the deep convection scheme have been introduced since Gregory and Rowntree (1990), such as the addition of down-drafts (Gregory and Allen 1991), convective momentum transport using a flux gradient approach (Stratton et al. 2009) and a convective available potential energy (CAPE) closure scheme, based on Fritsch and Chappell (1980a, b), which uses a dilute CAPE calculation. In the default MetUM GA3 configuration, the time scale for the CAPE closure is set at 90 min unless large-scale vertical velocities over $0.3 \mathrm{~m} \mathrm{~s}^{-1}$ are detected in the column, in which case the time scale is reduced to ensure numerical stability. To study the sensitivity to horizontal resolution alone, it is important to keep these parameters as constant as possible across configurations. To ensure numerical stability at all the resolutions studied here, the maximum CAPE time scale is decreased to $60 \mathrm{~min}$ and the threshold vertical velocity is increased to $0.4 \mathrm{~m} \mathrm{~s}^{-1}$ across all configurations.

Convection can also occur at the grid-scale and targeted horizontal diffusion of moisture is applied above a certain vertical velocity threshold to dissipate very high vertical velocities and maintain numerical stability. This threshold is increased with resolution to allow resolution of finer scale features in the vertical flow (targeted diffusion W threshold in Table 2).

\subsection{Analysis techniques}

\subsubsection{Tracking synoptic systems}

Analysis of synoptic systems in the monsoon trough uses a tracking algorithm (TRACK-1.4.0, Hodges 1994; Roberts et al. 2015) on 6-hourly $850 \mathrm{hPa}$ relative vorticity. The data are first filtered to T42 resolution (approximately $2.8^{\circ}$ in latitude and longitude). This coarse resolution filtering is a typical approach applied in tropical cyclone tracking to remove sub-synoptic-scale noise from the relative vorticity fields (e.g. Bengtsson et al. 2006; Strachan et al. 2013). The common spatial filter also reduces resolution dependence in the tracking procedure. Intense monsoon depressions and less intense monsoon lows have a typical length-scale of 1000-2000 km (e.g. Sikka 1977; Krishnamurthy and Misra 2010), which is several times the T42 grid-spacing.

Tracking parameters were chosen based on validation with ERA-Interim reanalysis $\left(1^{\circ}\right.$ gridded product regridded to T42 for tracking). Systems that exceed a (cyclonic) vorticity threshold of $3 \times 10^{-5} \mathrm{~s}^{-1}$ for at least 2 days and that travel a minimum distance of $5^{\circ}$ are diagnosed. The distance travelled threshold is applied to the greatest distance found between any two points in the system's trajectory. To affect South Asia in a meaningful way, we require that the system spends at least $60 \%$ of its lifetime in between $70^{\circ}$ $95^{\circ} \mathrm{E}$ and $10^{\circ}-30^{\circ} \mathrm{N}$. A further criterion is applied to differentiate fully recirculating systems from other instances of vorticity variability such as (diurnal) variations in the monsoon trough, variations in the heat low development over India during the early monsoon, and small-scale features developing near Himalayan orography. The recirculation criterion requires the presence of flow reversal in both zonal and meridional directions, with the absolute value of the flow exceeding $5 \mathrm{~m} \mathrm{~s}^{-1}$ in both directions within a box approximately $10^{\circ}$ around each system and lasting continuously for 1 day.

Validation of this method applied to ERA-Interim reanalysis against the Indian Meteorological Department (IMD) Cyclone and Monsoon Depression eAtlas (IMD 2011) shows reasonable agreement, with most systems travelling a substantial distance across India diagnosed. Our method also identifies weaker monsoon lows that traverse a substantial part of India in ERA-Interim re-analysis and substantially contribute to monsoon rainfall. However, these systems are absent in the IMD dataset as they do not qualify as monsoon depressions. Several relatively 
stationary depressions in the IMD dataset over the northern Bay of Bengal are not diagnosed in ERA-Interim due to the minimum distance threshold, which is necessary to avoid multiple erroneous inclusions. Likewise, stationary monsoon lows are not included.

LPS rainfall is estimated in a box approximately $10^{\circ}$ around each system, which estimates the typical lengthscale of monsoon depressions and lows.

\subsubsection{Significance testing}

To test for significance with respect to ensemble member, we use a Mann-Whitney rank sum test (Mann and Whitney 1947; Kanji 2006). This test ranks members of two samples in ascending size and uses the relative positions of the two samples in the rank to determine the significance of the difference between the two samples.

\subsection{Observational datasets}

We compare the MetUM output to many observational products. To assess seasonal mean precipitation we use the Global Precipitation Climatology Project (GPCP) Version 2.2 Monthly Precipitation Analysis (Adler et al. 2003). GPCP is a $2.5^{\circ}$ gridded merged analysis that incorporates precipitation estimates from low-orbit satellite microwave data, geostationary satellite infrared data and surface rain gauge observations. To estimate observational error, we also use the monthly CPC Merged Analysis of Precipitation (CMAP) product, a similar gauge and satellite analysis (Xie and Arkin 1997). We interpolate MetUM output to the GPCP and CMAP grid for comparison.

To assess daily precipitation, we use the $1^{\circ}$ daily gridded product GPCP Version 1.2 (Huffman et al. 2001), which is available from 1996 to the present. We also use the $0.5^{\circ}$ daily gridded APHRODITE dataset, version APHRO_MA_ V1003R1 (which has better quality control, incorporates more data, and has had bugs corrected when compared with APHRO_MA_V0902, Yatagai et al. 2009). APHRODITE is primarily derived from rain gauges and is available over land only from 1951 to 2007. Both daily datasets were interpolated to the N96 grid for comparison with MetUM data.

To assess latent heat fluxes over the Maritime Continent we used monthly $1^{\circ}$ gridded output from the Objectively Analysed air-sea Heat Fluxes (OAFlux) project, available from 1958 to 2012. OAFlux products are constructed over the ocean from an optimal blending of satellite retrievals and three atmospheric reanalyses (Yu 2007; Yu et al. 2008). To assess surface wind speeds, we used the Scatterometer Climatology of Ocean Winds (SCOW) product, derived from 122 months (September 1999-October 2009) of QuikSCAT scatterometer data and available over the ocean only (Risien and Chelton 2008). SCOW monthly $0.25^{\circ}$ gridded fields were interpolated to N96 for comparison to MetUM output.

For fields that are not directly observable, including winds on many pressure levels, we use two reanalysis products: the European Centre for Medium-Range Weather Forecasts' (ECMWF) ERA-Interim atmospheric reanalysis product gridded to $0.70 \times 0.70^{\circ}$ (Dee et al. 2011) and the NASA's Modern-Era Retrospective Analysis for Research and Applications reanalysis product gridded to $0.67 \times 0.50^{\circ}$ (MERRA, Rienecker et al. 2011). Fields were interpolated to N96 grid, compared over an equivalent time period and compared on equivalent pressure levels unless otherwise stated.

\section{Resolution sensitivity of the South Asian monsoon}

\subsection{JJAS mean state}

In Fig. 2 we show climatological and ensemble averaged JJAS precipitation in the Indo-Pacific region for GPCP, CMAP and the N96, N216 and N512 configurations of the MetUM. We also show the differences between configurations and each configuration's bias relative to GPCP and CMAP. In GPCP and CMAP, precipitation maxima lie over the eastern equatorial Indian Ocean, over and off the west coast of the Indian peninsula and in the western Bay of Bengal. The MetUM shows significant biases in these regions, in particular, excess precipitation over the equatorial Indian Ocean; a deficit of precipitation over the eastern Arabian Sea, Indian peninsula and Bay of Bengal; and excess precipitation over the southern slopes of the Himalayas.

Increasing resolution produces consistent small changes in precipitation over large areas including precipitation increases in the southeast Arabian Sea, over India and over east Africa; precipitation decreases over the equatorial Indian Ocean, South China Sea and western Pacific; and precipitation increases over the Maritime Continent islands. The largest grid-point changes in precipitation tend to be over steep gradients in orography, and often consist of a large precipitation increase next to a large precipitation decrease where the orographic precipitation has shifted closer to the orography. Increasing resolution from N96 to N216 introduces larger changes than increasing resolution from N216 to N512. This suggests resolution sensitivity decreases at higher resolution.

These precipitation changes are not necessarily improvements. The precipitation deficit over India and the precipitation excess over the equatorial Indian Ocean are both slightly reduced, but this comes at the cost of increasing 


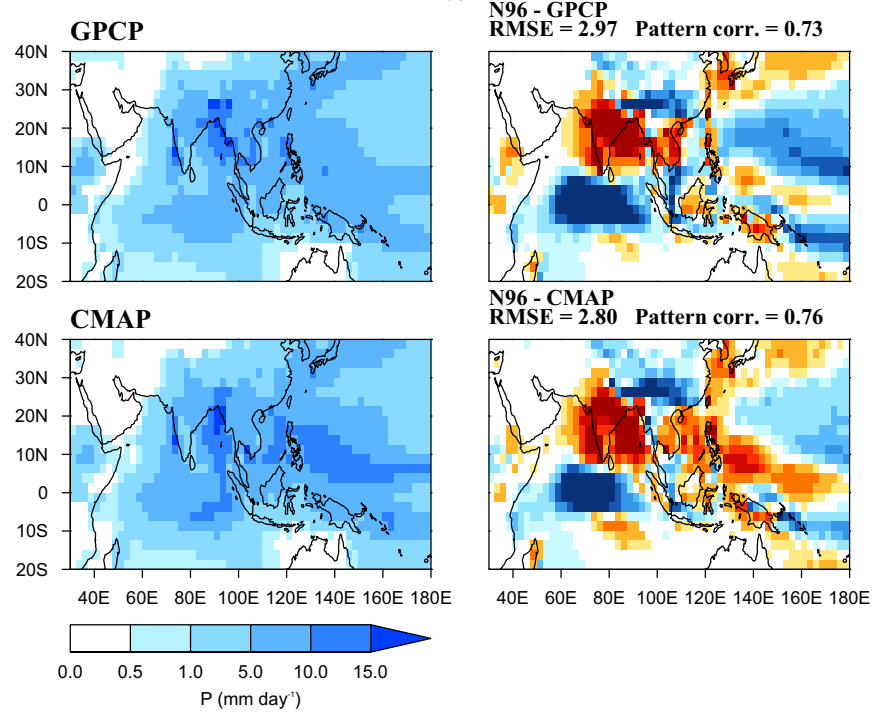

Fig. 2 Diagonal and left Climatological JJAS precipitation in GPCP and CMAP and ensemble averaged climatological JJAS precipitation in the N96, N216 and N512 configurations of the MetUM, all on their native grids, in the tropical Indo-Pacific. Off diagonal, top two rows Differences between each of the MetUM configurations. The higher resolution data is interpolated to the lower resolution MetUM grid for comparison. Shaded grid points in the difference panels indi-

precipitation biases over the western equatorial Pacific. Over the entire domain of Fig. 2, the root mean square error increases and the pattern correlation decreases, despite interpolating all configurations to the same resolution, indicating an overall increase in biases.

To examine the changes in South Asian monsoon circulation, in Fig. 3 we show the JJAS ensemble averaged climatology of MetUM $850 \mathrm{hPa}$ wind at N96, the change


N216 - N96@ N96

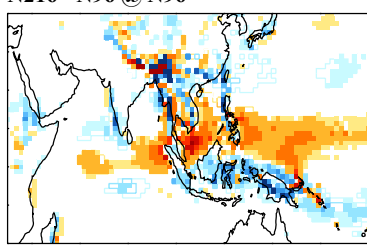

RMSE $=3.32$

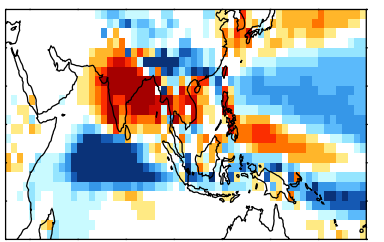

N216-CMAP

Pattern corr. $=0.68$

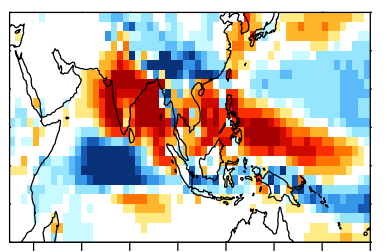

40E 60E 80E 100E 120E 140E 160E 180E
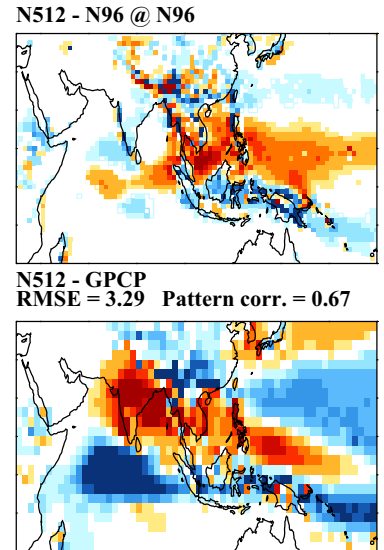

N512 - CMAP
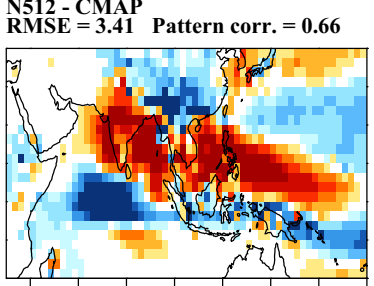

40E 60E 80E 100E 120E 140E 160E 180E $\begin{array}{llllll}-5.0 & -3.0 & -1.0 & 0.5 & 2.0 & 4.0\end{array}$

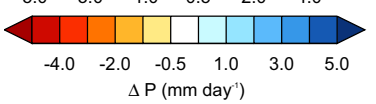

cate precipitation differences are significant at the $95 \%$ level using a Mann-Whitney rank sum test, less significant changes are outlined. Off diagonal, bottom two rows Biases between each configuration of the MetUM with respect to GPCP and CMAP observations. RMSE and pattern correlations over the entire domain are listed above these panels

when the resolution is increased to N512 and the bias with respect to ERA-Interim (N96 and N512 climatological $850 \mathrm{hPa}$ winds are compared later in Fig. 10). These are overlaid on the comparable JJAS precipitation map for reference. The largest changes in circulation are also near steep orography, such as the East African Highlands and the Hadramawt mountains on the Arabian peninsula. In the Arabian Sea, there is a strengthening and northward shift 


\section{(a) $\mathrm{N96}$}

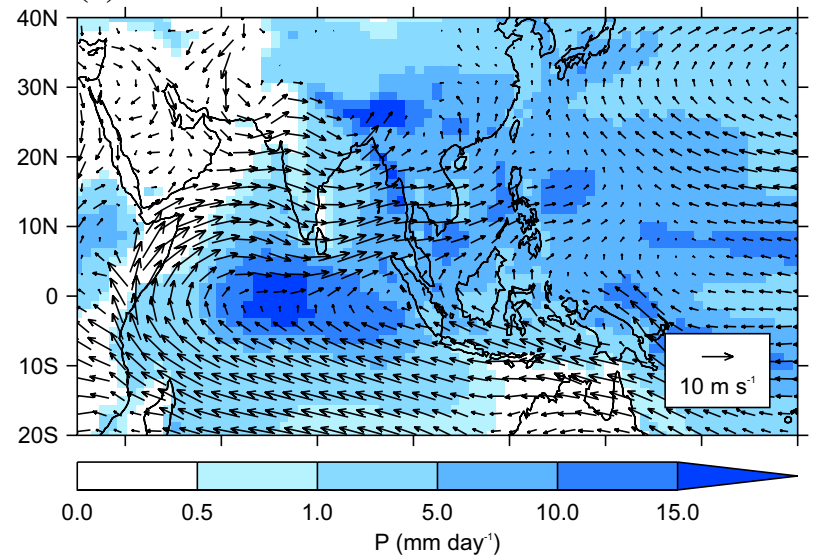

(b) N512-N96

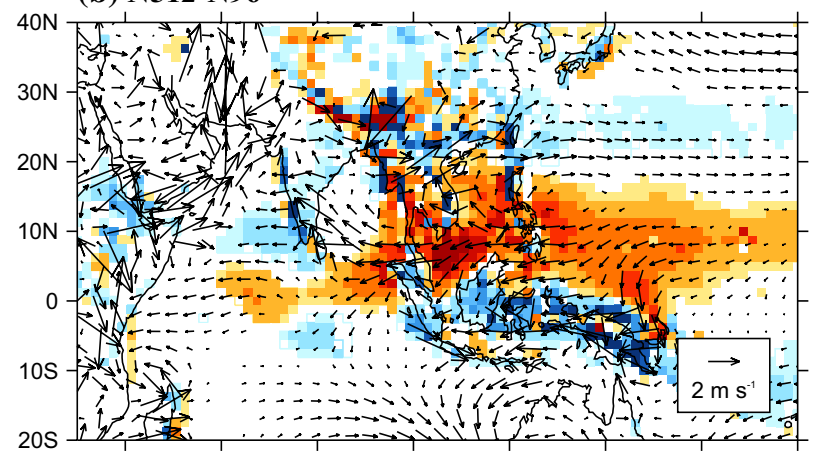

(c) $\mathrm{N} 96$ bias

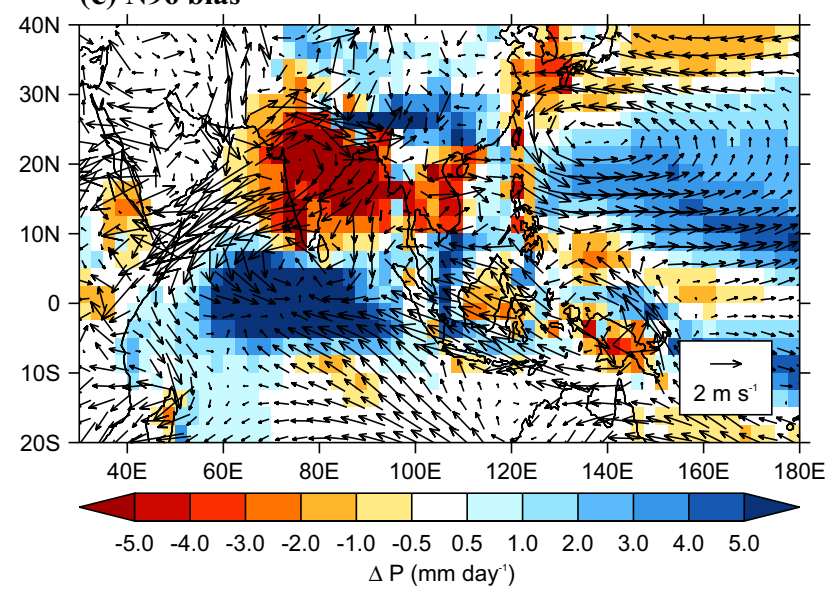

Fig. 3 a Ensemble averaged climatological JJAS precipitation $\left(\mathrm{mm} \mathrm{day}{ }^{-1}\right)$ and $850 \mathrm{hPa}$ winds $\left(\mathrm{m} \mathrm{s}^{-1}\right)$ in the $\mathrm{N} 96$ configuration of the MetUM. b Difference in ensemble averaged, climatological JJAS precipitation and $850 \mathrm{hPa}$ winds between the N512 and N96 MetUM configurations. c JJAS precipitation and $850 \mathrm{hPa}$ wind bias in the N96 configuration of the MetUM relative to GPCP and ERA-Interim. Shaded grid points in (b) indicate precipitation biases are significant at the $95 \%$ level using a Mann-Whitney rank sum test, less significant changes are outlined. Vectors are only shown in (b) if either the zonal or meridional wind differences are significant at the $95 \%$ level

of the Findlater/Somali Jet off the coasts of Africa and the Arabian peninsula, which is an improvement in the weak Somali Jet bias. As with precipitation, there are also smaller changes over larger areas. Decreased westerlies extending from the African coast to the West Pacific are consistent with the reduction in precipitation and diabatic heating in the equatorial Indian Ocean and West Pacific. Increased southerly wind components in the southern Bay of Bengal and South China Sea, and decreased southerly wind components just south of the equator are also all consistent with the precipitation changes in the equatorial Indian Ocean, West Pacific and over the Maritime Continent.

On average, the GCMs in CMIP5 have higher atmospheric horizontal resolution than the GCMs in CMIP3. While the slight improvements over the equatorial Indian Ocean and India are consistent with the differences between the CMIP3 and CMIP5 multi-model mean (MMM) bias, the overall increase in bias is inconsistent with the difference between the CMIP3 and CMIP5 MMM (Sperber et al. 2013). While the CMIP5 GCMs are usually coupled and the UPSCALE integrations are atmosphereonly, this indicates that increasing atmospheric resolution is one plausible cause for increasing precipitation over India in the CMIP5 GCMs. Consistency with other individual GCM resolution sensitivity studies is discussed in Sect. 5.2.

\subsection{Seasonal cycle}

The South Asian monsoon onset occurs over the Andaman Sea in the southeast Bay of Bengal in late May and covers most of the Bay of Bengal and the southern tip of the India peninsula by the end of May. It progresses northward and westward to cover the entire Indian peninsula by mid-July. After the onset, there is competition between the equatorial Indian Ocean convergence zone and the Indian subcontinent convergence zone (Gadgil and Sajani 1998), which supplies monsoon precipitation and drives intraseasonal variability. The onset and the two convergence zones are visible in the annual cycle of precipitation averaged from $70^{\circ}$ to $90^{\circ} \mathrm{E}$, which is shown in Fig. 4 for GPCP and the MetUM N96, N216 and N512 configurations. AGCMs (e.g. Gadgil and Sajani 1998) and coupled GCMs (e.g. Sperber et al. 2013) typically struggle to correctly simulate the timing of the onset and the competition between the convergence zones. Figure 4 shows that the MetUM is no exception. There is extremely low precipitation over India throughout the season, except for intense precipitation over the southern slopes of the Himalayas, and excessive precipitation over the equatorial Indian ocean, consistent with the JJAS mean precipitation in Fig. 2. When resolution increases, little improvement is seen in the competition between the continental and oceanic convergence zones, but there are indications that the monsoon onset is slightly improved, with increased precipitation in May from $5^{\circ}$ to $15^{\circ} \mathrm{N}$, which is highlighted in Fig. 4.

To analyse the detailed seasonal cycle over India, a time series of climatological N96, N216, N512, GPCP and 
(a) GPCP



(c) $\mathrm{N} 216$

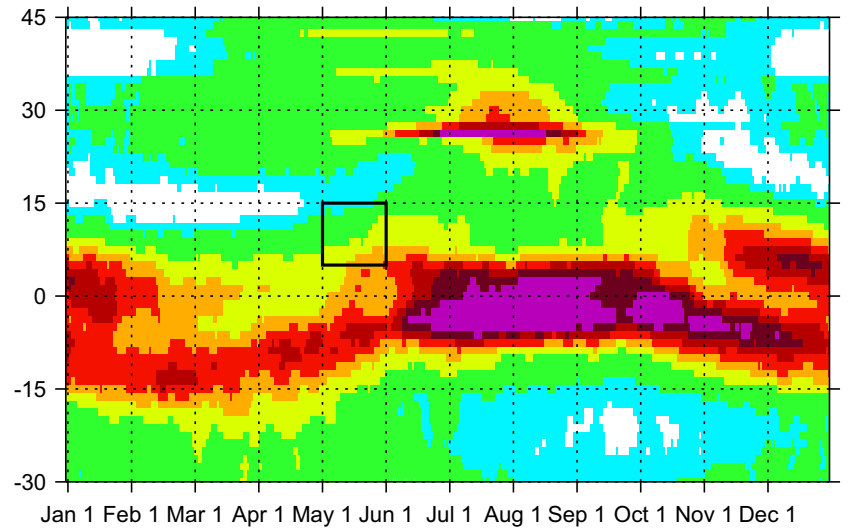

(b) $\mathrm{N96}$

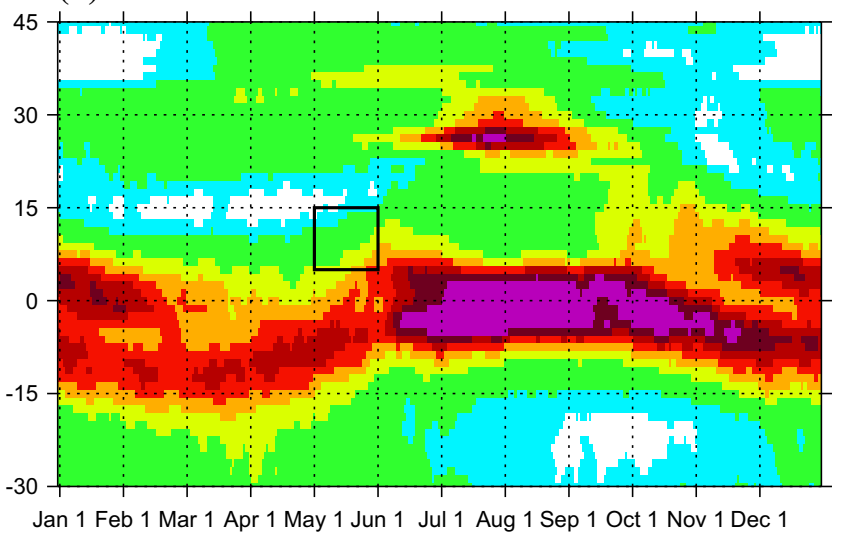

(d) $\mathrm{N} 512$

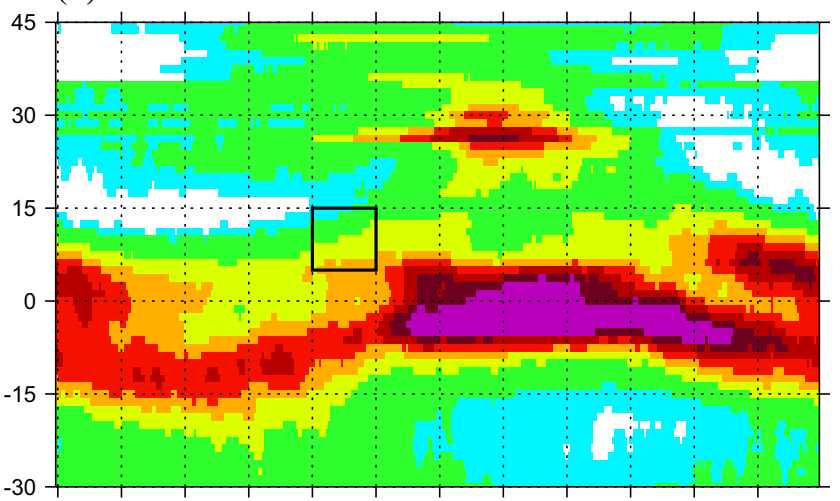

Jan 1 Feb 1 Mar 1 Apr 1 May 1 Jun 1 Jul 1 Aug 1 Sep 1 Oct 1 Nov 1 Dec 1

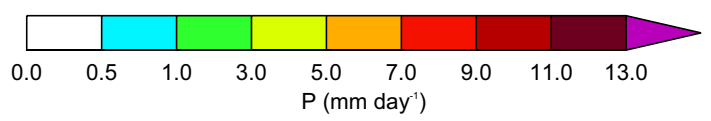

Fig. 4 Seasonal cycle of climatological precipitation averaged from $70^{\circ}$ to $90^{\circ} \mathrm{E}$ in (a) GPCP (1997-2011) and the (b) N96, (c) N216 and (d) N512 configurations of the MetUM (1985-2011, ensemble aver-

APHRODITE daily precipitation averaged over the India peninsular land south of $25^{\circ} \mathrm{N}$ and west of $90^{\circ} \mathrm{E}$, excluding the dominant orographic precipitation over the Himalayas, are shown in Fig. 5. The large precipitation deficit over India in all configurations of the MetUM is clear, but as resolution increases, precipitation increases from May through August. The increase is at most $1.5 \mathrm{~mm} \mathrm{day}^{-1}$, a small fraction of the precipitation bias over India in the MetUM. However, it nearly doubles the precipitation at N96 and as such represents a meaningful improvement for model development. The increase is largest in June and July, giving a moderately more accurate distribution of precipitation through the season.

\subsection{Interannual and intraseasonal variability}

The largest driver of Indian monsoon interannual variability is the teleconnection with the El Niño Southern Oscillation age). All fields are interpolated to the N96 grid for comparison. The box highlights an increase in precipitation early in the season

(ENSO, e.g. Webster and Yang 1992; Kumar et al. 2006). Coupling to a dynamical ocean is required to accurately simulate the teleconnection between ENSO and the monsoon domain (Bracco et al. 2005; Wang et al. 2008), but the relationship between prescribed Pacific SSTs and the South Asian monsoon may still change as resolution is increased in the AGCM. To check the sensitivity of the monsoonENSO teleconnection to resolution, we calculated the lagcorrelation of JJAS all-India rainfall and the JJAS WebsterYang dynamical monsoon index (Webster and Yang 1992) with seasonal Niño 3.4 SST in each ensemble member at each resolution (not shown). Due to the small number of years available in our ensemble, we found no statistically significant change in either relationship with resolution.

To check for changes in intraseasonal variability we also analysed the northward and eastward propagation of the BSISO using the lag-correlation of 20-100 days bandpass filtered precipitation in each ensemble member averaged 


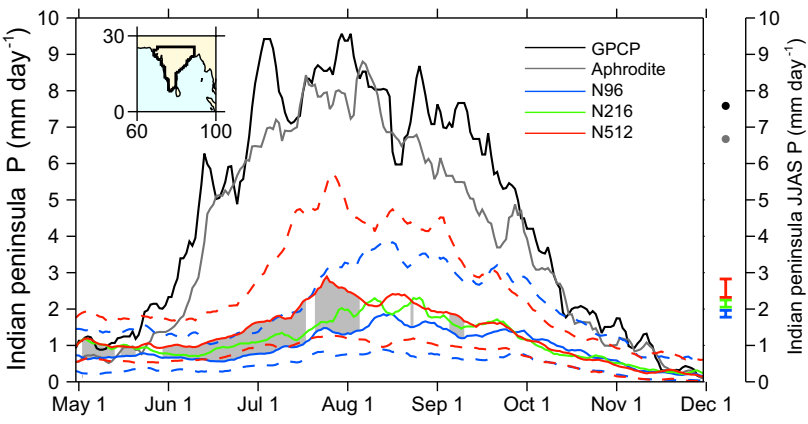

Fig. 5 Five day running median of climatological daily precipitation over the Indian peninsula (region outlined in the inset diagram) in GPCP (1997-2011, black), APHRODITE (1985-2007, grey), N96 (blue), N216 (green) and N512 (red) configurations of the MetUM (1985-2011, ensemble average). All fields are interpolated to the N96 grid for the comparison. The first and third quartiles are shown for $\mathrm{N} 96$ and $\mathrm{N} 512$ as the dashed lines. The area between the N96 and N512 time series is shaded if the difference between N96 and N512 is significant at the $95 \%$ level by a Mann-Whitney rank sum test. The coloured error bars to the right of the figure indicate the ensemble spread of the JJAS mean MetUM precipitation, and the dots indicate GPCP and APHRODITE JJAS mean precipitation

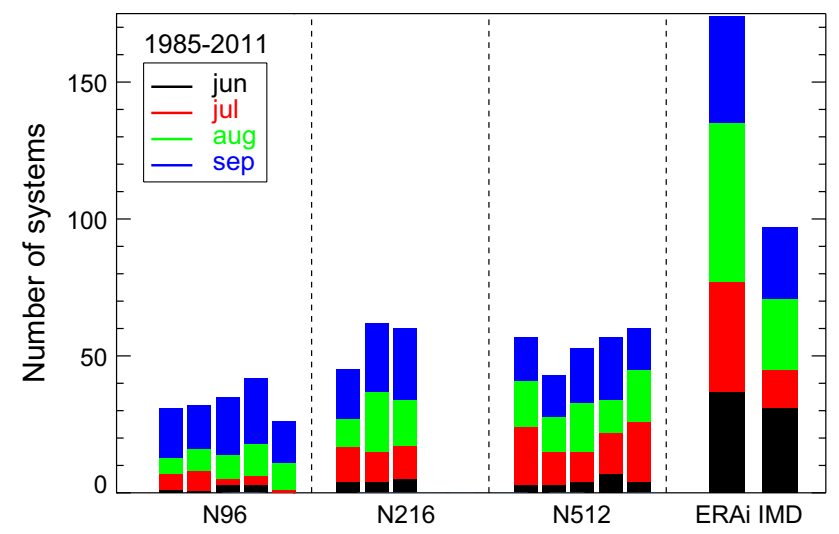

Fig. 6 Total number of monsoon LPS in each MetUM integration, including five ensemble members for N96 and N512 and three ensemble members for $\mathrm{N} 216$. Also shown are numbers of monsoon LPS in ERA-Interim reanalysis and the IMD e-atlas. Colours indicate the month in which the system initiated. There are fewer systems in the IMD e-atlas than ERA-Interim because the IMD e-atlas only contains the more intense monsoon LPS classified as depressions

over $70^{\circ}-100^{\circ} \mathrm{E}$ and $5^{\circ} \mathrm{S}-5^{\circ} \mathrm{N}$, respectively (not shown). In each case, very little resolution sensitivity was seen, consistent with other resolution sensitivity studies (Bacmeister et al. 2014).

\subsection{Monsoon low pressure systems}

As described in Sect. 2.3.1, we use the tropical cyclone tracking software TRACK to identify monsoon LPS. The total number of monsoon LPS in each month of JJAS for


Fig. 7 Climatological, ensemble averaged JJAS precipitation attributed to monsoon LPS in the a N96 configuration of the MetUM on its native grid and b N512 configuration of the MetUM interpolated to the N96 grid. c Difference between $\mathbf{b}$ and a. Only points significant by a Mann-Whitney rank sum test are shown. The colour scale ranges to $\pm 1.5 \mathrm{~mm}$ day $^{-1}$, while the scale on Fig. 3, which shows the total JJAS precipitation change with resolution, ranges to $\pm 5 \mathrm{~mm} \mathrm{day}^{-1}$

each MetUM ensemble member, ERA-Interim reanalysis and the IMD e-atlas of observed depressions is shown in Fig. 6. Consistent with previous studies with the MetUM and other GCMs (Ashok et al. 2000; Sabre et al. 2000; Stowasser et al. 2009), there are far fewer LPS detected in the MetUM than in ERA-Interim or the IMD e-atlas, and the resolution sensitivity is very small compared to the size of the bias. Variation between ensemble members is also large compared to the resolution sensitivity. Numbers of LPS in JJA increase from N96 to N216, consistent with other GCMS (Kitoh and Kusunoki 2004; Sabin et al. 2013), while they stay approximately the same from N216 to N512. In September, the number of LPS tends to decrease slightly as resolution increases from N96 to N216 and again to N512. TRACK may be detecting two distinct types of systems: monsoon LPS, which are mainly present in JJA, and tropical cyclones in the Bay of Bengal, which are mainly present in spring and autumn. This would explain the difference in resolution sensitivity between JJA systems and September systems. Analysis of tropical cyclones in the UPSCALE dataset indicates that tropical cyclone numbers in the northern Indian ocean decrease in SON when resolution is increased (Roberts et al. 2015), consistent with the decrease in September systems seen here.

We associate precipitation with the tracked LPS if it occurs at the same time as the vorticity anomaly and within a $10^{\circ}$ box centred on the LPS. The derived LPS precipitation in the N96 and N512 configurations of the MetUM and the difference between them is shown in Fig. 7. As resolution increases from N96 to N216 (not shown), and further to N512, changes in monsoon LPS contribute to increased rainfall in northern and eastern central India and decreased rainfall in the southern Bay of Bengal. When compared to the total precipitation change in Fig. 2, an increase in 


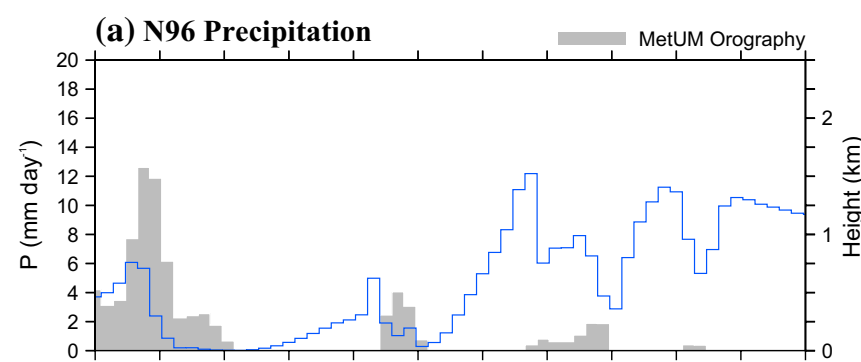

(b) N216 Precipitation

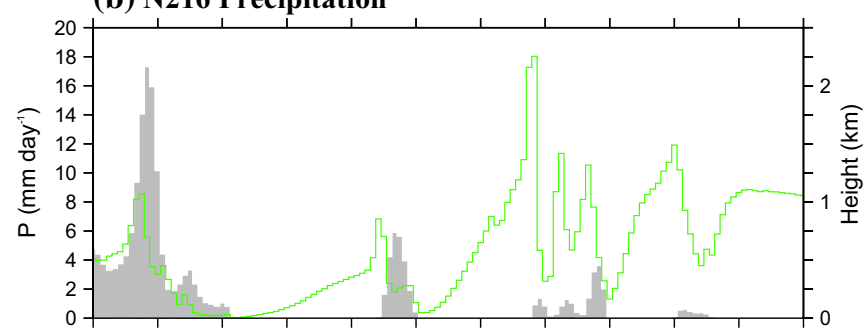

(c) N512 Precipitation



Fig. 8 Left Zonal transect of climatological ensemble mean JJAS precipitation averaged from $11^{\circ} \mathrm{N}$ to $13^{\circ} \mathrm{N}$ for the a N96, b N216 and $\mathbf{c}$ N512 configurations of the MetUM (coloured lines) compared to transects of the MetUM grid-box mean orographic height (shaded),

monsoon LPS may explain much of the increased precipitation over northeast India, but not over southern India. However, by necessity, the vorticity threshold used to track systems neglects any smaller, less intense or stationary systems that still contribute to the rainfall, and the resolution sensitivity of rainfall, over India.

The version of the MetUM we use here is known to have low numbers of tropical cyclones compared to observations (Roberts et al. 2015). It is likely that a GCM with an improved representation of tropical LPS may also show greater resolution sensitivity in the number of monsoon LPS. A detailed study of the intensity and lifetime of monsoon LPS is beyond the scope of this article. The resolution sensitivity of these properties will be discussed in a future article (Levine et al. in preparation).

\section{Analysis of sources of resolution sensitivity}

As discussed in Sect. 1, there are several ways in which increasing the horizontal resolution of the MetUM
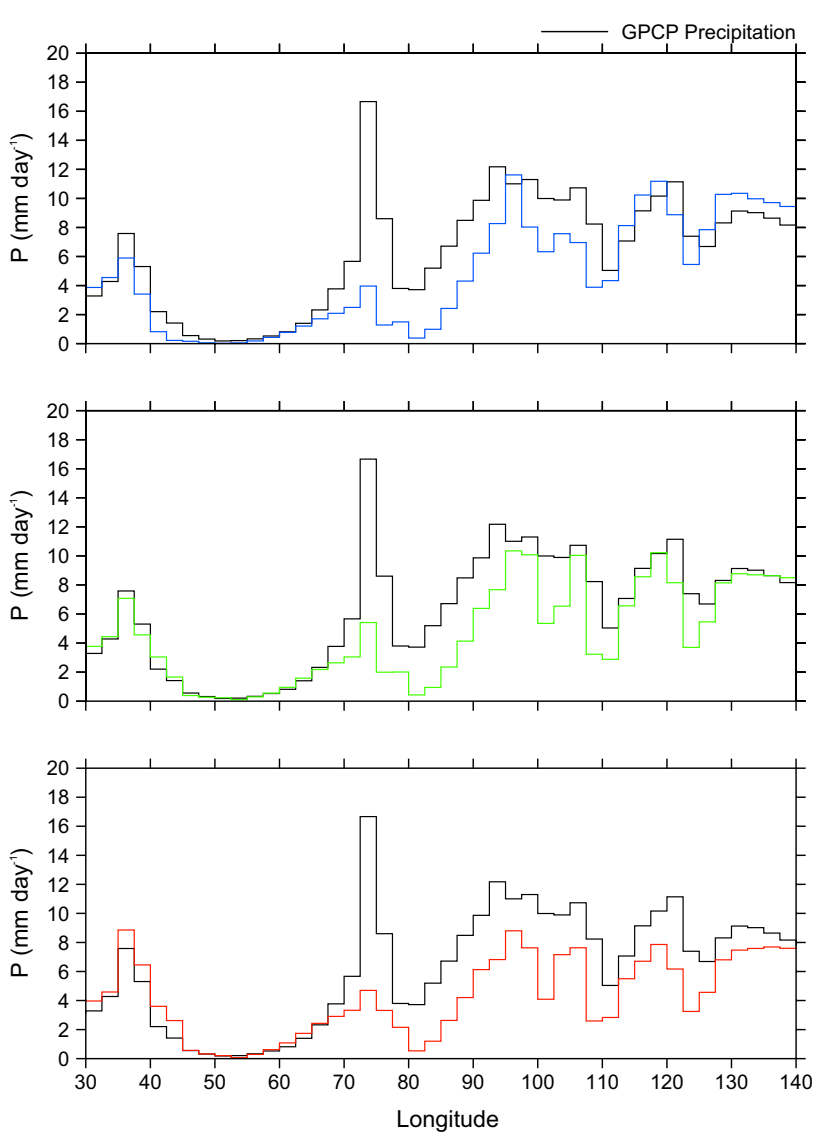

all on their native grid. Orographic features are labelled in (c). Right MetUM precipitation transects (colours) interpolated to the GPCP grid, compared to a transect of GPCP precipitation (black)

could change monsoon precipitation and circulation in the MetUM. In the following sections, we will attempt to determine the specific resolution-related changes in processes that generate the largest changes in precipitation and circulation described in Sect. 3. We analyse only the largest changes: changes in orographic precipitation (Sect. 4.1), changes in the monsoon circulation in the Arabian Sea (Sect. 4.1.2) and precipitation changes over the Maritime Continent region (Sect. 4.2). In Sect. 5 we speculate about how these processes interact to form the total monsoon domain response to increasing resolution.

\subsection{Orography and the South Asian monsoon}

We expect improved resolution of Asian and African orography will influence monsoon precipitation and circulation. In this section, we draw upon sensitivity experiments performed in other studies to understand how the improved resolution of different orographic features influences the monsoon in the MetUM. 

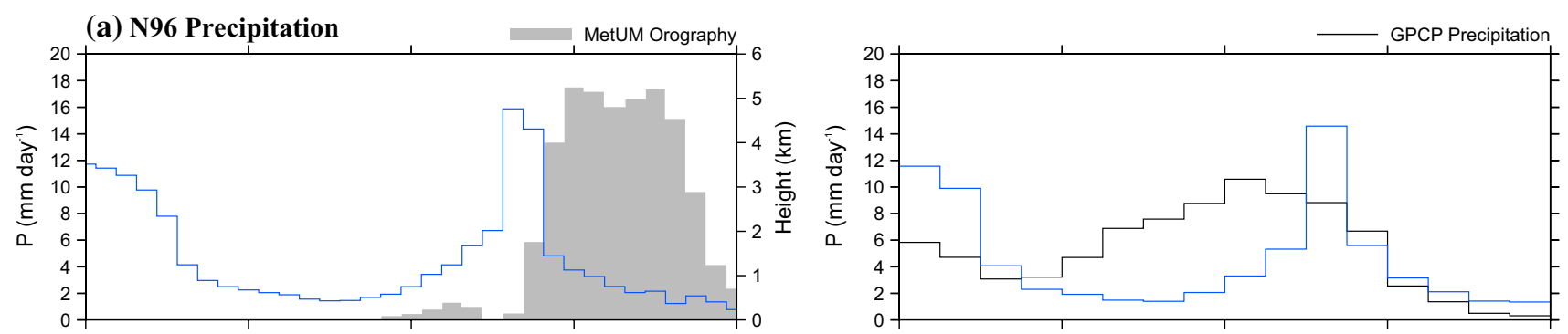

(b) N216 Precipitation

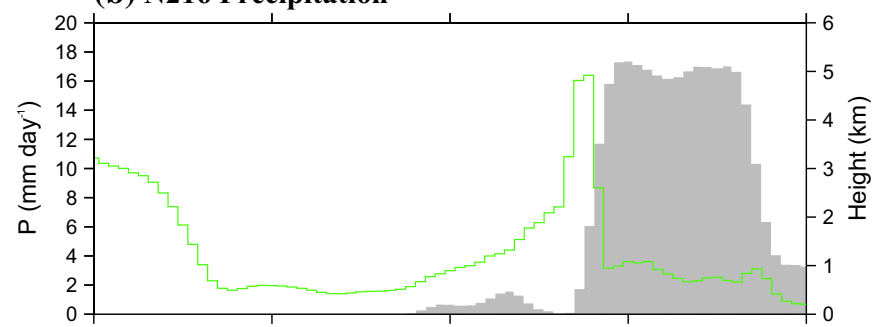

(c) N512 Precipitation



Fig. 9 Left Meridional transect of climatological ensemble mean JJAS precipitation averaged from $83^{\circ} \mathrm{E}$ to $87^{\circ} \mathrm{E}$ for the a N96, b N216 and c N512 configurations of the MetUM (coloured lines), compared to transects of the MetUM grid-box mean orographic height (shaded), all on their native grid. The large orographic feature

\subsubsection{South Asian monsoon orographic rainfall}

Xie et al. (2006) use tropical rainfall measuring mission (TRMM) observations to argue that when monsoon precipitation is examined on a fine scale, it is comprised of a distinct set of rain bands, each anchored to an orographic feature: the Western Ghats and Himalayas in India; the Arakan Yoma, Bilauktang, Cardamom, and Annaman Cordillera in Indochina and the Andaman and Philippine Islands in the surrounding seas. They also show, using sensitivity tests, that the correct orographically forced diabatic heating over the monsoon domain can improve the precipitation and large-scale circulation of the monsoon, especially in the Bay of Bengal.

As resolution is increased in the MetUM, these orographic features and their forcing of precipitation are resolved more accurately. In Fig. 8, we show a zonal transect of the grid-box mean orography and precipitation in the N96, N216 and N512 configurations of the MetUM at $12.5^{\circ} \mathrm{N}$, which crosses all of the orographic features listed
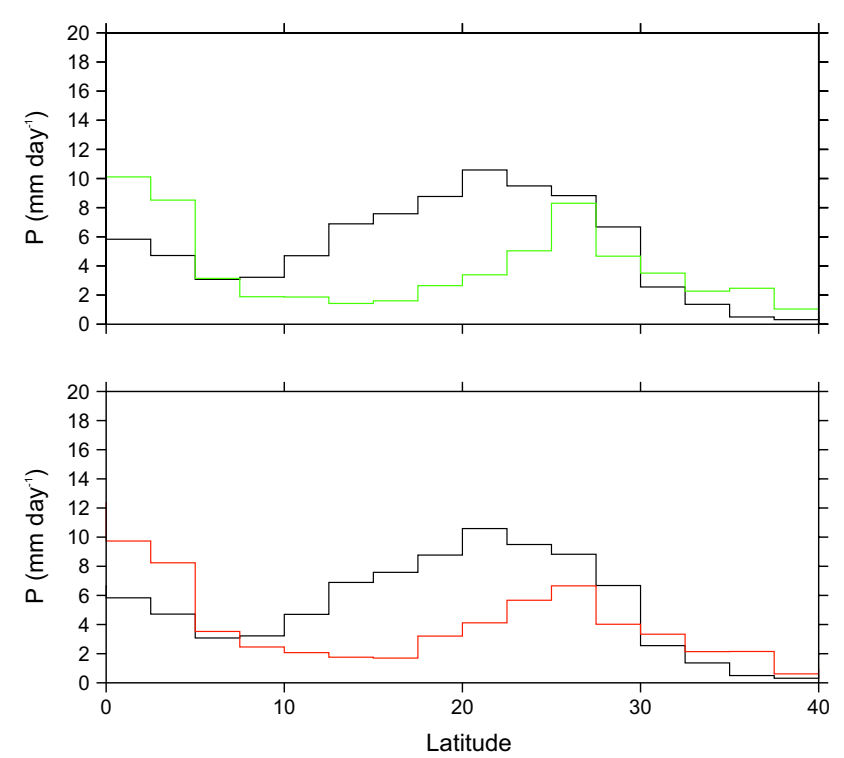

at approximately $25^{\circ}-40^{\circ} \mathrm{N}$ is the Himalayas and Tibetan Plateau. The lower altitude orography at approximately $20^{\circ}-25^{\circ} \mathrm{N}$ is the Deccan Plateau and Eastern Ghats on the Indian Peninsula. Right MetUM precipitation transects (colours) interpolated to the GPCP grid compared to a transect of GPCP precipitation (black)

above except the Himalayas. At N96 there are distinct orographic rain bands windward of well separated orographic features, such as the Western Ghats. Over closely spaced features, such as the three mountain ranges over Indochina, the orographic features, and consequently the rain bands, blend together in the N96 configuration. As resolution increases, the orographic height of each mountain range increases and the valleys between the mountain ranges appear. This leads to distinct orographically forced rain bands, with larger maxima windward of the orography, and lower minima leeward or over the orography. Consequently, while there is a predictable increase in maximum precipitation windward of orographic features, consistent with resolution sensitivity seen in the CMIP3 models (Kim et al. 2008), precipitation integrated over the orographic feature may not change due to the combination of the improved resolution of the rain band windward of the orography and improved resolution of the rain shadow leeward of the orography. When the transects are interpolated to the GPCP resolution and compared to GPCP precipitation 
(a) ERA-Interim

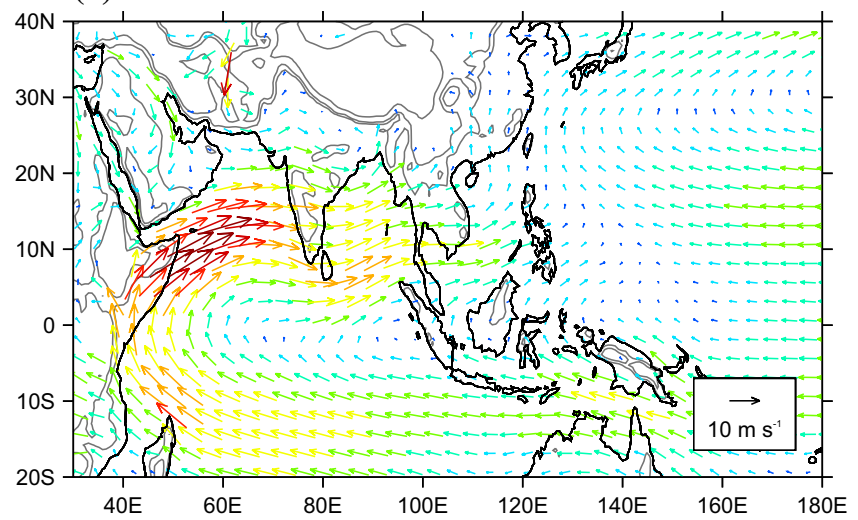

(c) $\mathrm{N} 216$

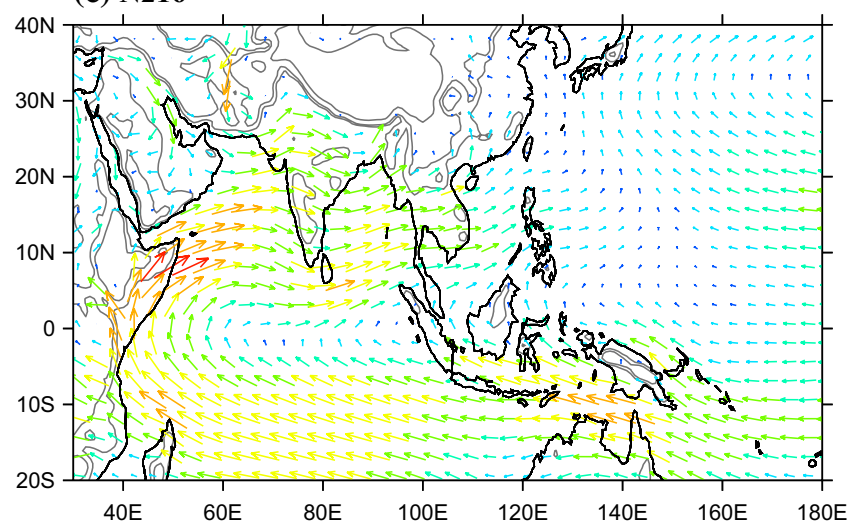

(b) $\mathbf{N 9 6}$



(d) $\mathrm{N} 512$

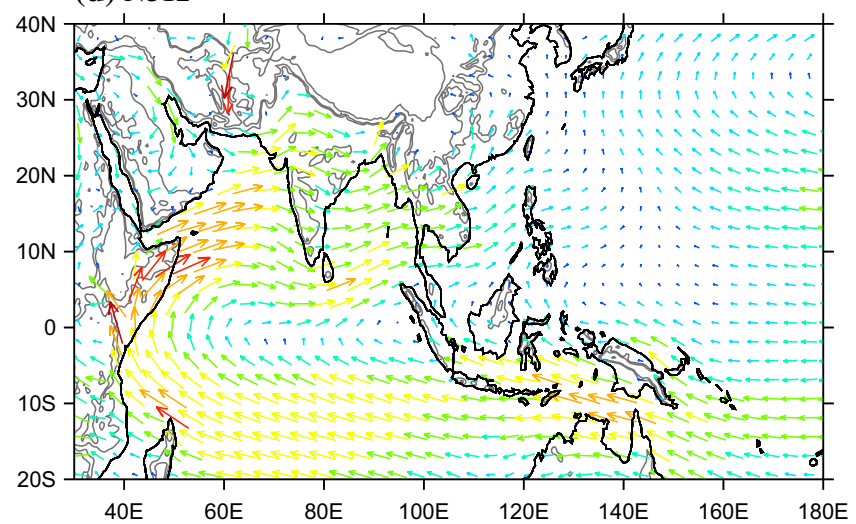

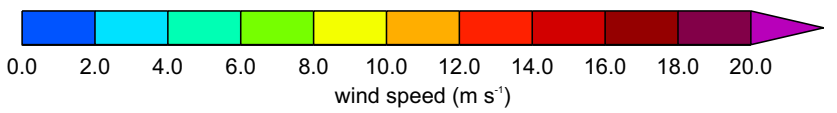

Fig. 10 Climatological JJAS $850 \mathrm{hPa}$ circulation in a ERA-Interim reanalysis and b N96, c N216 and d N512 configurations of the MetUM (ensemble averaged) all interpolated to the N96 grid. Vectors are coloured according to wind speed. Grid-points that are below the orography at $850 \mathrm{hPa}$ are omitted. Grey lines contour the MetUM and ERA-Interim orography on their native grid at $500 \mathrm{~m}, 1 \mathrm{~km}$ and $3 \mathrm{~km}$
(Fig. 8), the improved resolution of orographic rain bands has no systematic effect on precipitation biases near orographic features. In some cases, precipitation decreases when resolution increases, such as off the west coast of Indochina $\left(95^{\circ}-100^{\circ} \mathrm{E}\right)$. In some cases it increases, such as over the East African Highlands $\left(40^{\circ}-50^{\circ} \mathrm{E}\right)$. This does not appear to correlate with the sign of the bias, but is generally consistent with the broader precipitation changes in the region. This suggests that while orographic rain bands are better resolved at high resolution across South Asia, the integrated change in precipitation over an orographic feature depends on the interaction with the large-scale circulation.

In Fig. 9, we show a meridional transect of the orography and precipitation at $85^{\circ} \mathrm{E}$ in the N96, N216 and N512 configurations of the MetUM. This transect crosses the Himalayas and the Tibetan Plateau, which are the tallest and broadest orographic feature in the region. Again, the peak in precipitation windward of the orography increases and narrows with resolution, and the trough in precipitation over the orography deepens with resolution. However, the change in maximum precipitation rate on the native grid, $2 \mathrm{~mm}$ day $^{-1}$, is much more modest than seen in Fig. 8. This may be because the representation of the Himalayas changes little, compared to features like the mountain ranges over Indochina, when resolution is increased. The Tibetan Plateau is a particularly large, smooth feature; degrading it to lower resolution does not change its maximum orographic height or number of peaks by very much. This contrasts to the previously shown changes over Indochina, where larger changes in maximum precipitation on the native grid are seen as rain bands and rain shadows become distinct at higher resolution. The wind direction is along, rather than perpendicular to, the Himalayas on this transect, which may also reduce the resolution sensitivity of the orographically forced precipitation here. 
(a) ERA-Interim

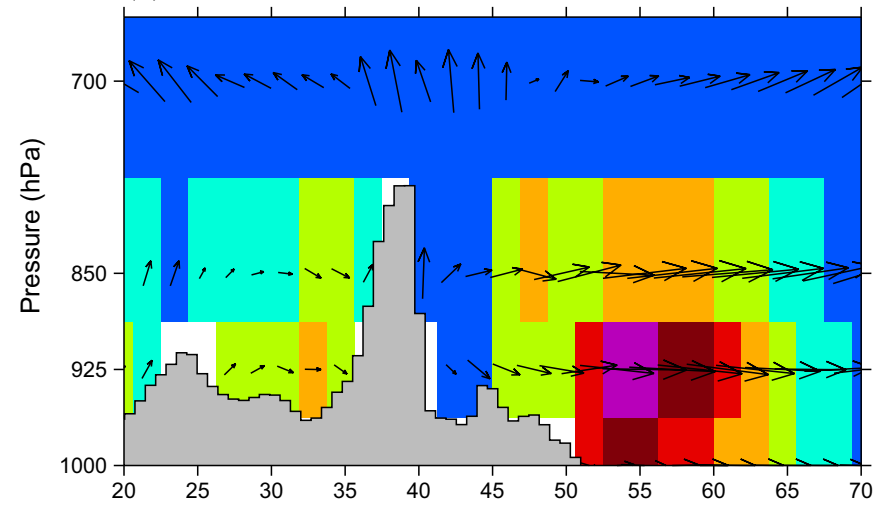

(c) $\mathrm{N} 216$

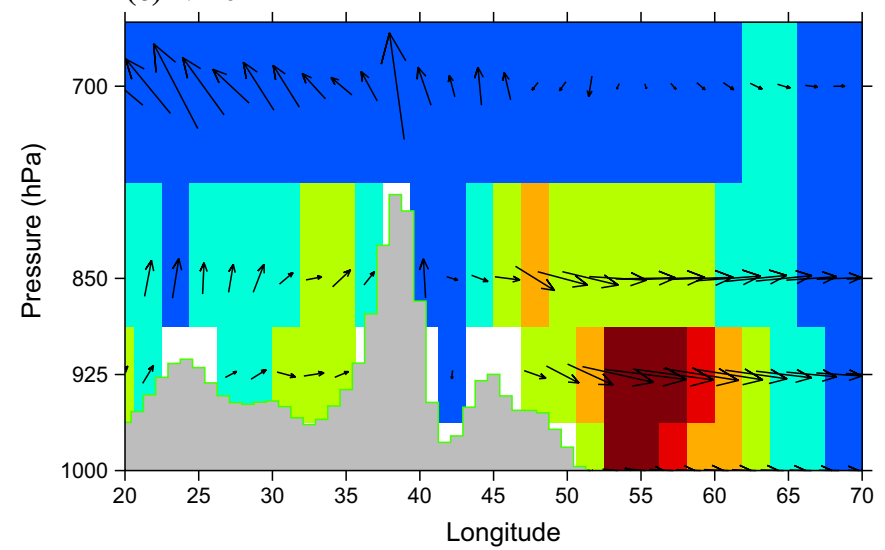

(b) $\mathrm{N96}$

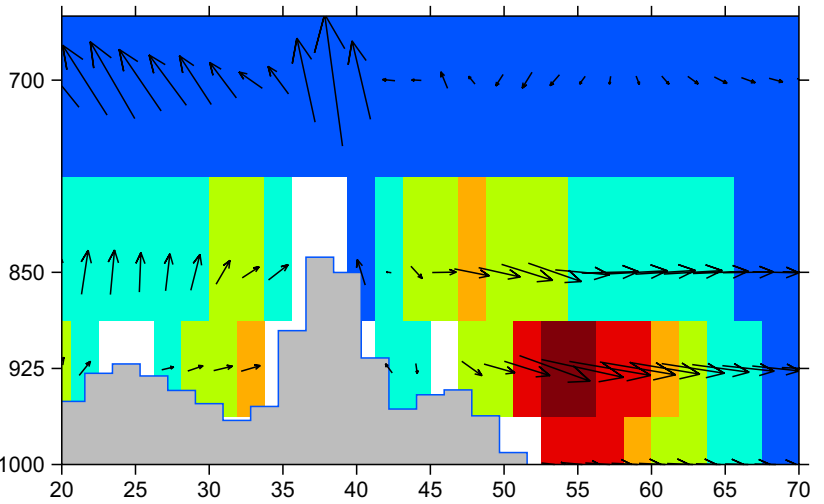

(d) $\mathrm{N512}$



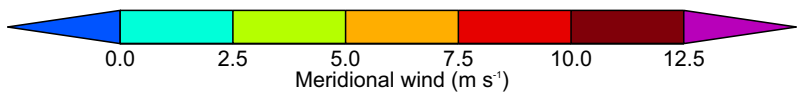

$\stackrel{\uparrow}{\longrightarrow} \mathrm{m} \mathrm{s}$

Fig. 11 Climatological JJAS 1000, 925, 850, and $700 \mathrm{hPa}$ meridional (colours, $\mathrm{m} \mathrm{s}^{-1}$ ), zonal (vectors, $\mathrm{m} \mathrm{s}^{-1}$ ) and vertical wind transects (vectors, $\mathrm{Pa} \mathrm{s}^{-1}$ ) averaged from $10^{\circ} \mathrm{N}$ to $15^{\circ} \mathrm{N}$ for a ERA-Interim and the b N96, c N216 and d N512 configurations of the MetUM (ensemble averaged). All fields have been interpolated to the N96

When the transect is compared to the GPCP transect on the GPCP grid, there is a marked decrease in integrated rainfall windward of the Himalayas as resolution is increased. This again demonstrates that orographic precipitation does not always increase as resolution is increased.

\subsubsection{East African highlands and the Somali Jet}

The East African Highlands (EAH) are mountain ranges in Ethiopia, Uganda, Kenya and Tanzania, directly west of where the Findlater/Somali Jet crosses the equator as it turns anticyclonically towards South Asia. Sensitivity tests with the MetUM and other models have shown that in the absence of the EAH and the Hadramawt mountains (Yemen) on the Arabian peninsula, the cross-equatorial flow decreases in velocity and extends in a broad swath across equatorial Africa (Hoskins and Rodwell grid. Also shown is a transect of the grid-box mean orography (grey) in each model configuration on its native grid. If a pressure level is below the orography at any time that grid-point point is shown in white

1995; Rodwell and Hoskins 1995; Slingo et al. 2005; Chakraborty et al. 2006). These highlands also have a pronounced effect on the South Asian monsoon circulation as it crosses the Arabian Sea and Indian peninsula. Rodwell and Hoskins (1995) used a global primitive equation model forced by summer monsoon diabatic heating to show that the orographic drag of the EAH alters the sign of the jet's potential vorticity as it crosses the equator, allowing it to remain in the northern hemisphere. Slingo et al. (2005) further showed in a full GCM that the EAH introduce a stationary wave in the monsoon circulation that extends from the Arabian Sea to the South China Sea and beyond.

Ensemble mean $850 \mathrm{hPa}$ wind vectors, coloured by wind speed, are shown in Fig. 10 for the N96, N216 and N512 configurations of the MetUM and ERA-Interim reanalysis. In all MetUM configurations the Findlater/Somali Jet is too weak, with maximum wind speeds of approximately 
(a) ERA-Interim



(c) N512

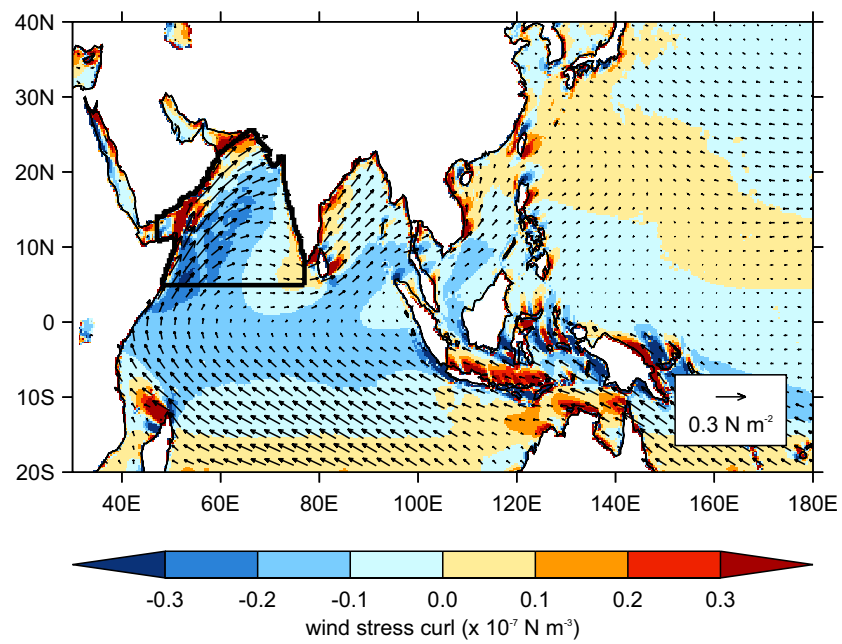

Fig. 12 Indo-Pacific JJAS wind stress (vectors) and wind stress curl (contours) in a ERA-Interim reanalysis and the b N96 and c N512 configurations of the MetUM (ensemble averaged). d The seasonal cycle of the wind stress curl integrated over the Arabian Sea (outlined in black in a-c) in ERA-Interim (black) and the N96 (blue), N216

$14 \mathrm{~m} \mathrm{~s}^{-1}$ in the MetUM and approximately $17 \mathrm{~m} \mathrm{~s}^{-1}$ in ERA-Interim. However, the speed increases as resolution increases, particularly just to the north of Madagascar and just to the east of the EAH. Jet speeds also increase across the meridional extent of the Arabian Sea, and have increased wave-like structure over the tip of the Indian peninsula and into the southern Bay of Bengal, more similar to the structure in ERA-Interim. Northward flow along the Indus valley (Pakistan) also increases, increasing the southwesterly bias there. This could be related to the increased wind speeds in the Somali Jet, or flow being forced southwesterly by improved resolution of the Western Ghats. Wind speed also increases through narrow channels such as the Hindu Kush and the Turkana Channel in east Africa.

To examine the increased speed in the Findlater/Somali Jet, Fig. 11 shows a $5^{\circ}$ wide zonal transect of ensemble mean JJAS wind speed at $12.5^{\circ} \mathrm{N}$ in each MetUM (b) $\mathrm{N96}$

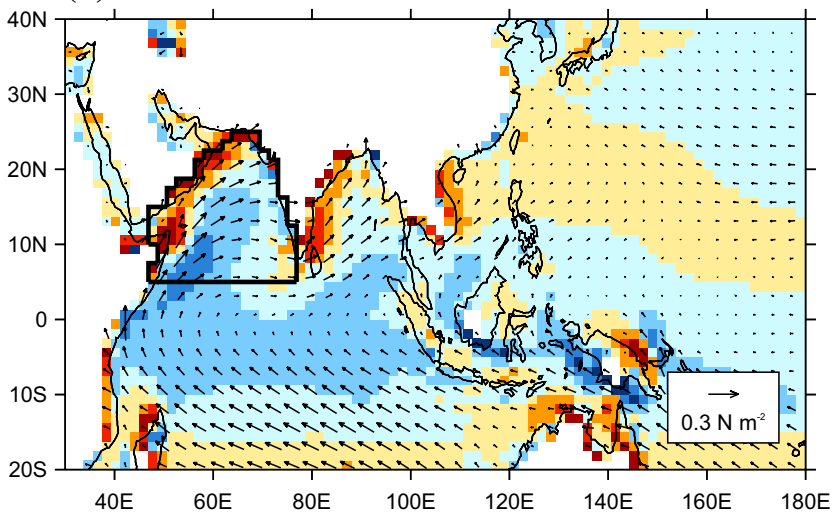

(d) Monthly integrated Arabian Sea wind stress curl



(green) and N512 (red) configurations of the MetUM. Each model is evaluated on its own grid to avoid interpolation effects over coastlines. The shaded area represents where the difference between N96 and N512 is significant by a Mann-Whitney rank sum test

configuration and ERA-Interim. A transect of the orography, including the EAH, is also shown. The maximum height of the highlands in this transect increases by over $700 \mathrm{~m}$ as resolution increases from N96 to N512. Somali Jet maximum velocities are shifted east and intensify, likely as a result of the increased confinement from the orography. The increased intensity of the jet is an improvement relative to ERA-Interim, while the eastward confinement, and consequent decrease in wind speeds around $50^{\circ} \mathrm{E}$, is detrimental.

Slingo et al. (2005) use sensitivity tests removing the EAH to show that the integrated wind stress curl in the Arabian Sea decreases (becomes more negative due to more clockwise curl) when the EAH are introduced, due to increased anticyclonic wind stress in the Arabian Sea from the standing wave introduced into the Somali Jet. In Fig. 12, we show the JJAS wind stress, JJAS wind stress 
(a) OAFlux observations

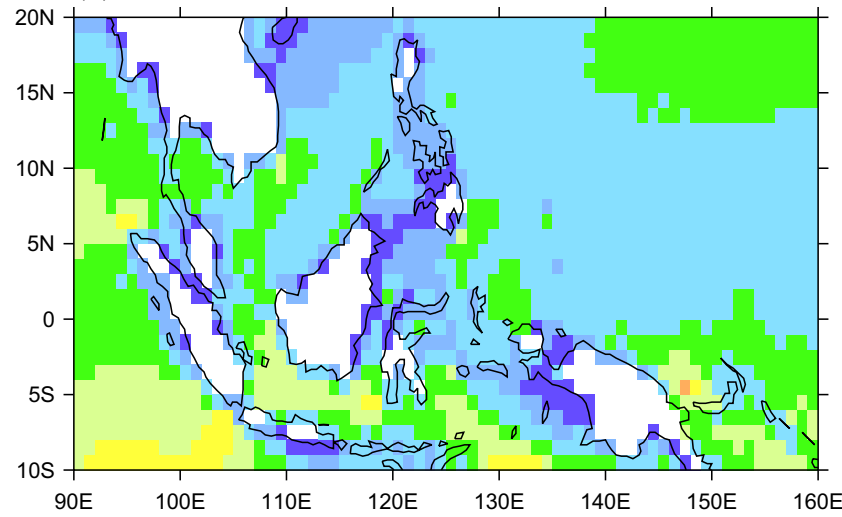

(c) $\mathrm{N} 216$

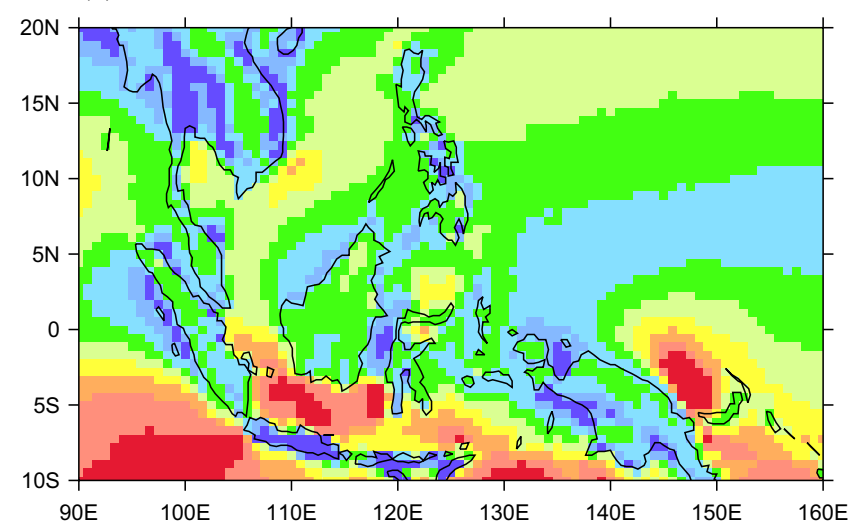

(b) $\mathbf{N 9 6}$

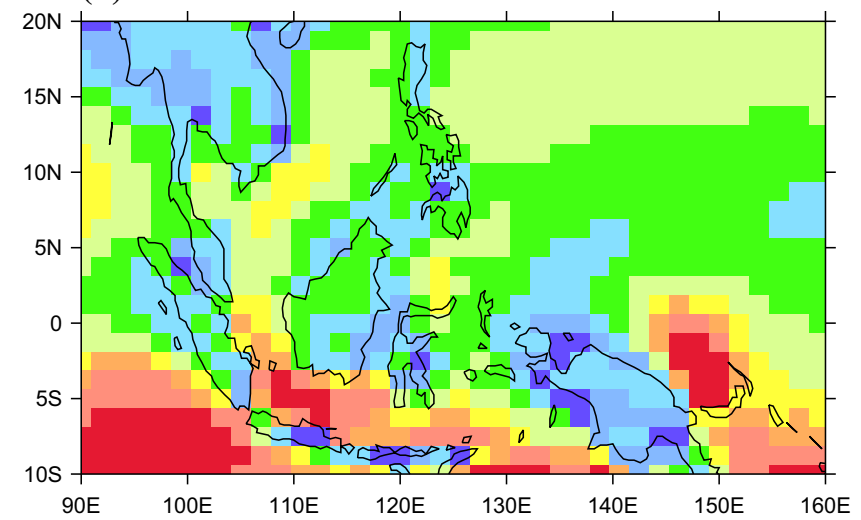

(d) $\mathrm{N} 512$

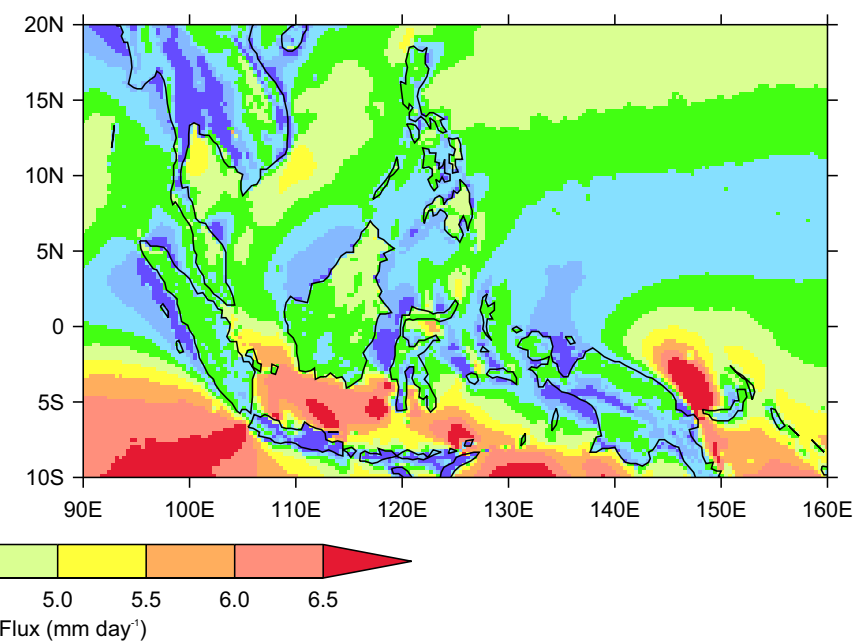

Fig. 13 JJAS latent heat flux $\left(\mathrm{mm} \mathrm{day}^{-1}\right.$ ) over the Maritime Continent region from the a OAFlux observations (1985-2011) over sea only, b N96, c N216 and d N512 configurations of the MetUM (1985-2011, ensemble average). All fields are shown on their native grid

curl and the annual cycle of the wind stress curl integrated over the Arabian Sea in the N96 and N512 configurations of the MetUM, as well as ERA-Interim. As resolution increases, the summer wind stress curl decreases, improving relative to ERA-Interim reanalysis. This indicates that, similar to introducing the EAH in Slingo et al. (2005), the increased resolution of the East African Highlands is improving the speed and curl of the Somali Jet.

\subsection{Maritime Continent and coastal tiling}

The largest area JJAS precipitation sensitivity to resolution in this study is the precipitation increase over Maritime Continent islands and the precipitation decrease over the northern seas of the Maritime Continent. Using sensitivity experiments, Schiemann et al. (2014) attributes a similar change in annual precipitation in their resolution sensitivity study with HadGEM1 (an older version of the MetUM, Johns et al. 2006), to the decreased influence of the MetUM coastal tiling scheme with resolution. In recent versions of the MetUM, grid points that contain sub-grid land and sea, including points with sub-grid scale islands, are designated "coastal" grid points, and their properties are an amalgam of land and sea properties (see Sect. 2.2.2 and Walters et al. 2011). Strachan (2007) and Schiemann et al. (2014) found that the coastal tiling scheme that calculated these combined properties generated unrealistically low latent heat fluxes on coastal grid points. At higher resolution, the coastal points with their low latent heat fluxes covered less area (see Fig. 1), increasing the mean latent heat flux and precipitation over the Maritime Continent.

The GA3 configuration of HadGEM3 used here includes a fix to the coastal tiling scheme ("buddy scheme", Sect. 2.2.2 and Walters et al. 2011) that raises the latent heat flux over coastal points (not shown). Building on past work, we reanalyse the precipitation sensitivity over the Maritime Continent in light of these alterations to the MetUM. 
(a) SCOW observations



(c) $\mathrm{N} 512$

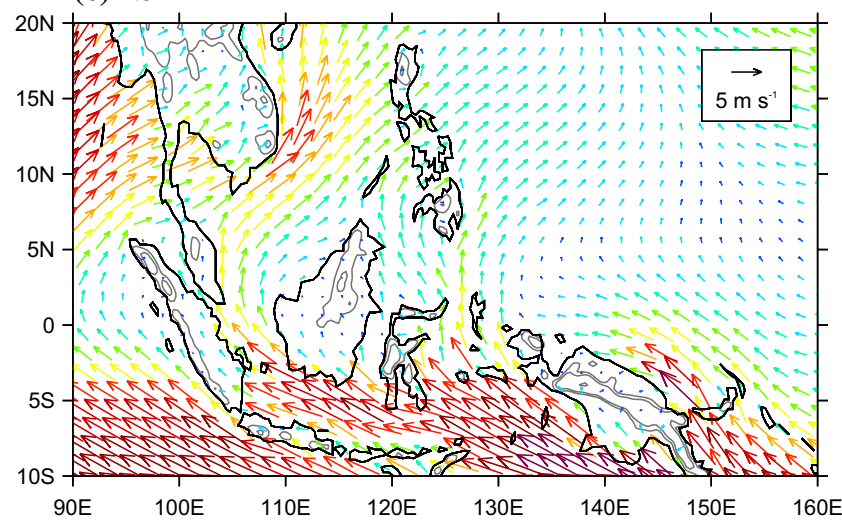

(b) $\mathrm{N96}$



(d) N512-N96

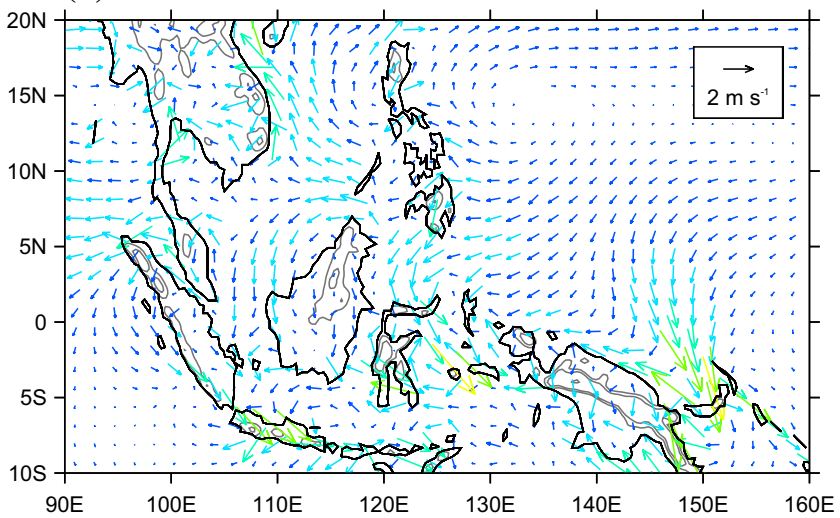

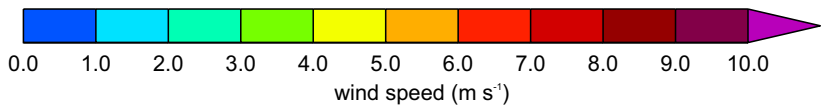

Fig. 14 a JJAS surface winds over the ocean from QuickSCAT (SCOW climatology 2000-2006) and JJAS $10 \mathrm{~m}$ winds for the b N96 and c N512 configurations of the MetUM over the Maritime Continent region (1985-2011, ensemble average). d The difference in $10 \mathrm{~m}$ wind in the N512 and N96 configurations. Note that the reference vector is $2 \mathrm{~m} \mathrm{~s}^{-1}$ in (d). All data are interpolated to the N96 grid for comparison. In all panels, vectors are coloured by wind speed. The MetUM grid-box mean orography is contoured at $500 \mathrm{~m}, 1 \mathrm{~km}$, and $3 \mathrm{~km}$ on the N96 grid in (b), and on the N512 grid in (c) and (d)
To confirm that introducing the buddy scheme has changed the Maritime Continent latent heat flux resolution sensitivity, we show the JJAS mean latent heat flux over the Maritime Continent in OAFlux observations and the N96, N216 and N512 configurations of the MetUM in Fig. 13. While the latent heat fluxes surrounding the islands in the MetUM are lower than over the islands and lower than over the surrounding seas, low latent heat fluxes do not appear to be confined to coastal grid points as in Schiemann et al. (2014). To determine the reasons for the low latent heat fluxes, we examined surface winds over the Maritime Continent. Figure 14 shows the JJAS $10 \mathrm{~m}$ circulation in the N96 and N512 configurations of the MetUM as well as the SCOW climatology of QuickSCAT observations. Overlaid are contours of Maritime Continent orography. Low $10 \mathrm{~m}$ wind speeds accompany the low latent heat fluxes, and the lowest wind speeds occur in the lees of the orography on the Maritime Continent. These lees gain definition at higher resolution as the orography and coastlines over the Maritime Continent contain increased detail.

An example is New Guinea, the large island roughly centred on $140^{\circ} \mathrm{E}$ and $5^{\circ} \mathrm{S}$, and the small, crescent shaped, New Britain island to its east. In Fig. 14, in the N96 configuration, the $10 \mathrm{~m}$ wind is southerly over central New Guinea, whereas in the N512 configuration, the wind is forced southeasterly, around the New Guinea Highlands. The northern branch of the flow is also guided by the orography on New Britain, and in the N512 configuration the wind is channeled tightly between New Britain and New Guinea. This increases the wind speed near the coast of New Guinea, and decreases it in the lee of New Britain. The adjustments 


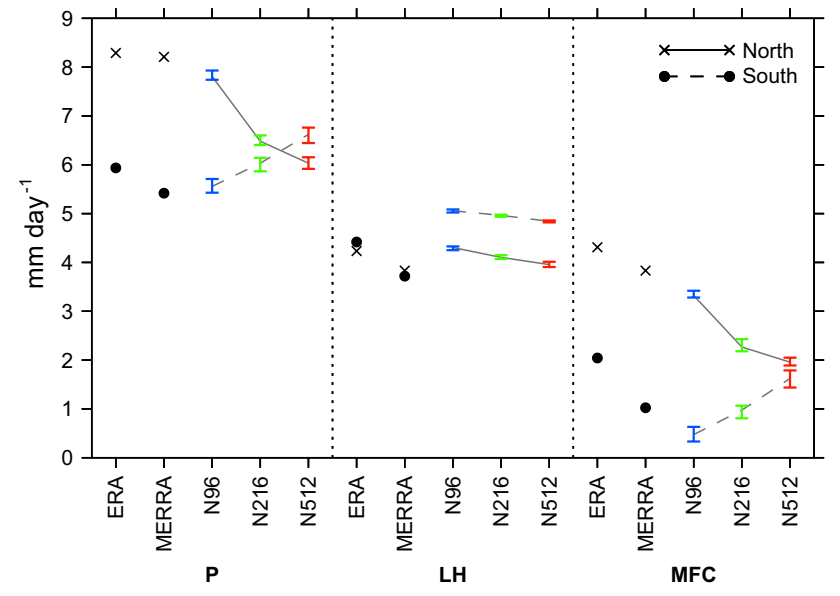

Fig. 15 Climatological JJAS column integrated moisture budgets including precipitation $(\mathrm{P})$, latent heat flux $(\mathrm{LH})$ and moisture flux convergence (MFC), averaged over grid-points in the Maritime Continent region $\left(90^{\circ}-160^{\circ} \mathrm{E}, 10^{\circ} \mathrm{S}-10^{\circ} \mathrm{N}\right.$, divided between northern and southern regions at the equator). ERA-Interim (black) and MERRA reanalysis (black) and the N96 (blue), N216 (green) and N512 (red) configurations of the MetUM are shown. For reanalysis, crosses represent averages north of the equator and dots represent averages south of the equator. For MetUM configurations, solid lines connect northern averages and dashed lines connect southern averages. The error bars show the spread in the MetUM ensemble

to the $10 \mathrm{~m}$ wind have a pronounced effect on the latent heat flux, shifting high latent heat fluxes north of New Guinea southward and lowering latent heat fluxes in the lee of New Britain.

Lower latent heat fluxes and adjusted $10 \mathrm{~m}$ wind speeds around the islands in the higher resolution MetUM configurations are overall in better agreement with the observational products. For example, leeward of New Britain, the latent heat flux and $10 \mathrm{~m}$ wind speed are much lower in OAFlux (Fig. 13) and QuikSCAT (Fig. 14) observations than in the MetUM at all resolutions. However, despite these improvements at higher resolution, latent heat flux and surface wind biases are still large, and the MetUM precipitation improves in some places and degrades in others (Fig. 3).
To explore the effect of improved resolution of Maritime Continent and Indochina orographic lees on the larger scale precipitation response, we examined the column-integrated moisture budgets over the northern Maritime Continent, where the precipitation decreases with resolution, and over the southern Maritime Continent, where precipitation increases with resolution. The budgets are averaged from $90^{\circ} \mathrm{E}$ to $160^{\circ} \mathrm{E}$ and from $10^{\circ} \mathrm{S}$ to $10^{\circ} \mathrm{N}$, divided between northern and southern regions at the equator (shown in Fig. 16). In Fig. 15, latent heat flux decreases as resolution increases both north and south of the equator, consistent with the maps in Figs. 13 and 14. This reduction in evaporation is much less than the reduction in precipitation north of the equator. The precipitation decrease is instead associated with a decrease in the moisture flux convergence north of the equator. South of the equator, the moisture flux convergence increases, which supplies the moisture for the precipitation increase there despite the evaporation decrease.

As resolution increases, average precipitation north of the equator worsens, evaporation south of the equator improves and moisture convergence north of the equator worsens relative to the reanalyses. However, the large difference between the reanalysis products prevents a clear comparison for other terms. Latent heat flux and $10 \mathrm{~m}$ wind speed maps of ERA-Interim and MERRA reanalysis, comparable to Figs. 13 and 14, show large discrepancies in regional features as well. Some regions in the analysis agree better with the MetUM, while others agree better with OAFlux and SCOW (not shown).

In Table 3 we list the JJAS precipitation and latent heat flux averaged over land and sea grid-points separately, defined on the native model grid, in the N96, N216 and N512 configurations. Precipitation over land increases both north and south of the equator, while precipitation over the sea decreases both north and south of the equator. This indicates a shift in the precipitation from sea to land. Latent heat flux also increases over land, consistent with the increased precipitation, and decreases over sea, both north and south of the equator. These changes indicate that the changes in the mean moisture budgets over the
Table 3 Ensemble averaged JJAS precipitation and latent heat flux $\left(\mathrm{mm} \mathrm{day}^{-1}\right)$ in the MetUM N96, N216 and N512 configurations averaged over all, land and sea points in the northern and southern regions of the Maritime Continent $\left(90^{\circ}-\right.$ $160^{\circ} \mathrm{E}, 10^{\circ} \mathrm{S}-10^{\circ} \mathrm{N}$, divided between northern and southern regions at the equator)

\begin{tabular}{|c|c|c|c|c|c|c|}
\hline & \multicolumn{2}{|l|}{ Total } & \multicolumn{2}{|l|}{ Land } & \multicolumn{2}{|c|}{ Ocean } \\
\hline & $\mathrm{P}$ & $\mathrm{LH}$ & $\mathrm{P}$ & LH & $\mathrm{P}$ & $\mathrm{LH}$ \\
\hline \multicolumn{7}{|l|}{ North } \\
\hline N96 & 7.81 & 4.31 & 6.27 & 4.10 & 8.39 & 4.36 \\
\hline N216 & 6.48 & 4.10 & 6.57 & 4.26 & 6.61 & 4.13 \\
\hline N512 & 6.03 & 3.96 & 7.32 & 4.40 & 5.83 & 3.91 \\
\hline \multicolumn{7}{|l|}{ South } \\
\hline N96 & 5.56 & 5.02 & 4.47 & 3.64 & 7.11 & 5.79 \\
\hline N216 & 6.03 & 4.96 & 6.20 & 3.76 & 6.36 & 5.53 \\
\hline N512 & 6.62 & 4.84 & 6.98 & 3.78 & 6.65 & 5.27 \\
\hline
\end{tabular}




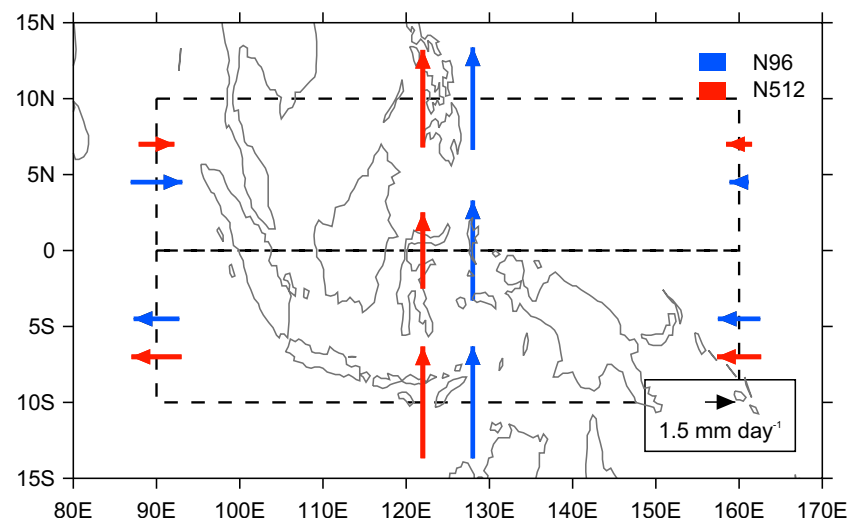

Fig. 16 Left Moisture flux from different directions into the Maritime Continent region $\left(90^{\circ}-160^{\circ} \mathrm{E}, 10^{\circ} \mathrm{S}-10^{\circ} \mathrm{N}\right.$ divided between northern and southern regions at the equator). The northern and southern regions of the Maritime Continent are marked by the grey dashed lines. Blue arrows indicate the moisture flux through each boundary in the N96 configuration of the MetUM, and red arrows

northern and southern Maritime Continent are related to the higher land fraction south of the equator than north of the equator. There is a very strong diurnal cycle over the Maritime Continent which is often incorrectly timed in GCMs including the MetUM (e.g. Yang and Slingo 2001). Analysis of the precipitation diurnal cycle at each grid point over the Maritime Continent (not shown) indicates that there is no resolution sensitivity of phase at these resolutions, simply a change in amplitude that is consistent with the mean precipitation change.

The increase in precipitation over land (Table 3) and the clear increase in the resolution of the lees of the mountainous Maritime Continent islands in Figs. 13 and 14, suggest that the increased resolution of orography is playing a role in the large-scale response. The orography over the Maritime Continent and the Indochina peninsula forms an arc of orographic features that inhibit the southerly and westerly flow into the South China Sea and the northern seas of the Maritime Continent. This analysis suggests that the increasing influence of these features at higher resolution causes increased moisture convergence and precipitation on the windward side of the orography, which leads to decreased moisture availability on the leeward side, causing reduced precipitation. Figure 16 shows the moisture flux into the northern and southern Maritime Continent from different directions in the N96 and N512 configurations of the MetUM. While the moisture flux into the southern Maritime Continent from the south changes very little, the flux from the south to the north of the Maritime Continent decreases by nearly $30 \%$. The westerly moisture flux into the northern Maritime Continent also decreases by about $30 \%$. Both of these reductions are likely due to a combination of increased precipitation windward of orography

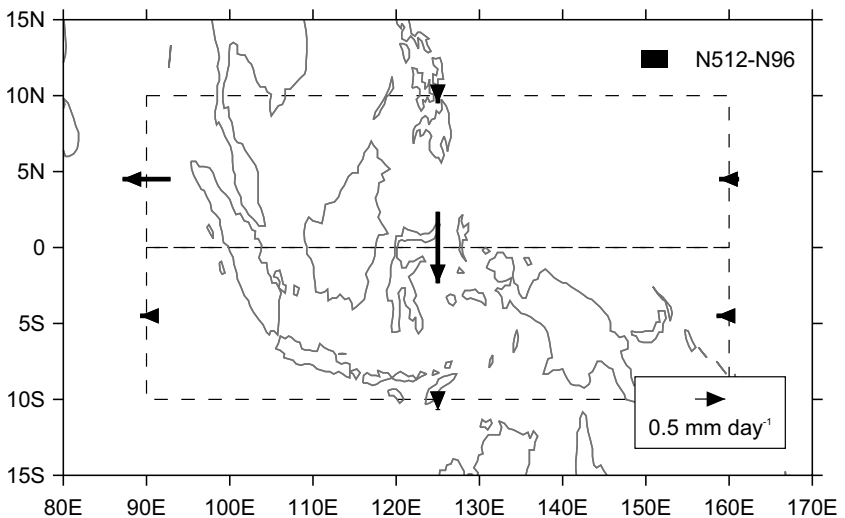

indicate moisture flux in the N512 configuration. Right Difference between N512 and N96 moisture flux through each boundary. Note the different scales in the two panels. The total moisture flux convergence increases by $1.03 \mathrm{~mm}$ day $^{-1}$ south of the equator and decreases by $1.39 \mathrm{~mm}$ day $^{-1}$ north of the equator, with the largest contribution coming from the change in moisture flux across the equator

decreasing moisture in the flow and decreased circulation strength due to the decreased latent heating associated with the reduced precipitation over the northern Maritime Continent. Similar shifts in precipitation over the Maritime Continent are seen in other GCMs (Bacmeister et al. 2014), perhaps suggesting that many GCMs are sensitive to increased resolution of orography in the Maritime Continent region.

\section{Discussion}

\subsection{Contributions to the total response}

To understand the resolution sensitivity of the South Asian monsoon, we quantified changes in precipitation and circulation between the N96, N216 and the N512 configurations of the MetUM on several time scales over the Indo-Pacific warm pool. We then diagnosed the processes responsible for the largest changes. Here, we combine the different aspects of our analysis to build an overall picture of the resolution sensitivity of the South Asian monsoon in the MetUM.

JJAS precipitation increases slightly over India when resolution is increased. While the precipitation change is small compared to the bias, and small compared to many other changes in Indo-Pacific JJAS precipitation, it is still a large fraction of the JJAS precipitation over India in the N96 configuration of the MetUM. We showed in Sect. 3.4 that monsoon LPS rainfall contributes to the precipitation increase over northern central India, but it does not contribute to the precipitation increase over southern India. No diagnostic we analysed suggested a clear cause for 
the improvement over southern India. It is likely due to a combination of the other changes discussed: changes in large-scale circulation related to the changes in precipitation over the Maritime Continent, changes in the Somali Jet and improved resolution of the Western and Eastern Ghats (mountain ranges on the west and east coasts of peninsular India). It is also possible that small organised systems of convection are better able to propagate to southern India over the Ghats from the west or from the Bay of Bengal to the east. Sensitivity experiments in a very similar N96 configuration of the MetUM indicate that the Western Ghats introduce a cyclonic perturbation over southern India and Sri Lanka, and an anticyclonic perturbation over northern India, with very little associated change in precipitation over southern peninsular Indian (Turner et al. 2015). These responses are not particularly consistent with the response seen in Fig. 3. This may indicate the increased resolution of the Western Ghats contributes little to the resolution sensitivity and the remote influences of the Maritime Continent and the Somali Jet contribute more. Due to the nonlinear interaction of the resolution-related changes it is difficult to establish conclusively.

Our analysis in Sect. 4.1.2 indicates the increased wind speed and wave structure in the Findlater/Somali Jet are due to the increased resolution of the East African Highlands and orography over the Arabian peninsula. In contrast, the changes over the Maritime Continent are likely due to a combination of processes. Our analysis in Sect. 4.2 suggests that the increased precipitation over the Maritime Continent islands and decreased precipitation north of the Maritime Continent are largely caused by improved representation of the orography over the Maritime Continent and Indochina peninsula, which increases convergence and precipitation over the orography and decreases the surface wind speed and latent heat flux in the lees of the orography. However, Schiemann et al. (2014) have shown that a similar pattern of precipitation changes is created due to improved the resolution of coastlines in an older version of the MetUM. Schiemann et al. (2014) attribute these changes to erroneously low latent heat fluxes on coastal grid-points that, thanks to an improvement in the scheme, are not present in our integrations. The integrations analysed here are also at higher resolution than the integrations analysed in Schiemann et al. (2014); coastal grid points occupy less area in our integrations and should contribute less to the resolution sensitivity. However, changes in the land fraction of grid-points as resolution increases may change the surface roughness, which could have a very similar effect to changing the orography. To diagnose the roles of the decreasing influence of the coastal tiling scheme and the increasing influence of the orography in our integrations, sensitivity experiments similar to those conducted in Schiemann et al. (2014) are underway with higher resolution and more recent versions of the MetUM (Johnson et al. in preparation).

Improved resolution of the atmospheric dynamics may also contribute to the resolution sensitivity. The JJAS precipitation decrease in the West Pacific and the equatorial Indian Ocean corresponds to a precipitation decrease at the centre of the inter-tropical convergence zone (ITCZ). Precipitation increases border the precipitation decrease to the north and south, perhaps indicating a broadening of the ITCZ as resolution increases. Global changes in zonal mean cloud and ascent indicate resolution sensitivity in the MetUM that is consistent with global changes in the ITCZ (Tsushima personal communication, 2014). In other GCMs, aqua-planet simulations at different resolutions have demonstrated that changing horizontal resolution and dynamical time-step can broaden or narrow the ITCZ, increase or decrease its peak and change its single or double peaked nature depending on how the dynamical core interacts with the parametrisation schemes (Williamson 2008; Landu et al. 2014; Zarzycki et al. 2014). Aquaplanet models of the version of the MetUM used here are needed to diagnose the contribution of ITCZ changes to the resolution sensitivity in the monsoon domain. However, consistent with Schiemann et al. (2014), precipitation changes in the warm pool region are larger than in other equatorial regions of the model (not shown). Consequently, if the ITCZ is changing shape with increasing resolution, the effect is amplified in the Indo-Pacific, likely through feedbacks with the processes discussed previously.

\subsection{Robustness of resolution sensitivity to GCM differences}

Resolution sensitivity in the South Asian monsoon domain depends on the resolutions analysed and the GCM used, but there are some commonalities across studies. The Somali Jet, due to its reliance on the orography in east Africa, often shows resolution improvements in speed and position (Sperber et al. 1994; Stephenson et al. 1998; Sabin et al. 2013). Studies in multiple versions of the MetUM (Schiemann et al. 2014; Johnson et al. in preparation) as well as other GCMs (Sabin et al. 2013; Bacmeister et al. 2014) show similar precipitation changes over the Maritime Continent.

The increase in precipitation over India in the MetUM is consistent with the resolution sensitivity of the annual precipitation range over India in the CMIP3 models (Kim et al. 2008). In other resolution sensitivity studies using individual GCMs, orographic rain bands over India tend to become more well defined, but the sign of precipitation changes over India are highly variable (Sperber et al. 1994; Stephenson et al. 1998; Delworth et al. 2012; Sabin et al. 2013; Bacmeister et al. 2014). This is 
also true within MetUM configurations. We analysed this MetUM configuration due to the ensemble of high resolution runs available in the UPSCALE dataset. The more recent GA6 version of the MetUM (Walters et al. 2015) which contains a new dynamical core and updates to the gravity wave drag scheme, shows a similar, slightly larger, resolution sensitivity over most of the South Asian monsoon domain. The response over India, however, is much larger (not shown). The reason for this is being explored in work focusing on monsoon LPS (Levine et al. in preparation).

\subsection{Shift in precipitation over land and sea}

Demory et al. (2014) and Schiemann et al. (2014) have shown in several versions of the MetUM that global precipitation shifts from sea to land as resolution increases. In the UPSCALE integrations, the fraction of global precipitation occurring over land increases from approximately $21.5 \%$ in the N96 configuration to $23 \%$ in the N512 configuration of the MetUM. The monsoon domain in JJAS is consistent with that global pattern, particularly over the Maritime Continent. It is not clear whether the local changes are a cause, an effect, or simply consistent with the global changes. It is possible that better resolution of orography in the tropics is causing more tropics-wide convergence, and consequently precipitation, over land. Future work will examine how much of the global precipitation shift this effect can explain.

\subsection{Comparison to MetUM biases}

We suggest that an improved representation of the orography has had a significant impact on the large scale in multiple regions. While this indicates improved resolution of a process, it does not necessarily improve the fidelity of simulated precipitation or circulation with respect to observations. For example, there is a deficit of precipitation in the N96 configuration of the MetUM in the northern seas of the Maritime Continent. While increased orographic flow blocking from the Maritime Continent and Indochina clearly improves the small-scale flows around the orography, our analysis suggests it further decreases rainfall north of the Maritime Continent, increasing the bias. This indicates that "low" resolution may compensate for other errors. As GCMs increase in resolution, deficiencies in parameterisations may become more, rather than less, apparent because many GCMs parameterisations were originally designed for low resolution. Scale-aware parameterisations may be necessary to realise the full potential of high resolution models for simulating the South Asian monsoon.

\section{Conclusions}

We have studied the sensitivity of South Asian monsoon domain rainfall to increasing horizontal resolution from approximately 200-40 km (N96-N512). We find a number of changes and, where diagnostics indicate a mechanism, suggest reasons for the changes:

- Small increase in precipitation over the Western Ghats, southern and central India.

- Improved representation of South Asian monsoon precipitation bands anchored to individual orographic features, but without a systematic change in the total amount of precipitation associated with orography.

- Increase in the speed and curvature of the Findlater/ Somali Jet, due to increased resolution of the East African Highlands and orography on the Arabian peninsula.

- Increased precipitation over and around the Maritime Continent Islands, most likely due to increased convergence over the better resolved Maritime Continent islands and orography.

- Decreased precipitation in the northern seas of the Maritime Continent due to decreased moisture flux into the region, likely because of increased precipitation over the better resolved Maritime Continent and Indochina peninsula orography. Decreased reliance on the coastal tiling scheme and sensitivity of the ITCZ shape to increased resolution may also play a role. Further work on disentangling these effects is in progress (Johnson et al. in preparation).

Each of these changes may be partly driven by, or contributing drivers for, global scale changes with resolution such as changes in the ITCZ (Williamson 2008; Landu et al. 2014) and a global shift of precipitation from sea to land (Demory et al. 2014; Schiemann et al. 2014).

At these resolutions, the increase in wind speed in the Somali Jet and the precipitation changes over the Maritime Continent are more similar across GCMs (Sabin et al. 2013; Bacmeister et al. 2014) than the resolution sensitivity of rainfall over India.

Similar changes occur when resolution is increased from $\mathrm{N} 216$ to N512 as occur when resolution is increased from N96 to N216. Increasing resolution at lower resolutions gives the largest benefit, but increasing resolution to $0.35^{\circ}$ continues to significantly redistribute tropical rainfall and consequently, diabatic heating.

As seen in previous studies, improvements as a result of increased resolution are small compared to Indian monsoon biases: the precipitation deficit over India, the excess precipitation over the Indian Ocean, and the weakness of the Somali Jet. Where changes are larger, such as over the Maritime 
Continent, some biases improve (increased precipitation over the islands), while some worsen (weak dry bias north of the Maritime Continent becomes a large dry bias). This is an indication that from 200 to $40 \mathrm{~km}$ resolution, increasing resolution is not a substitute for improving parameterisations, which may have a larger impact on South Asian monsoon biases.

The UPSCALE dataset can be obtained from: http://proj. badc.rl.ac.uk/upscale/wiki.

Acknowledgments S.J.B. and R.S. were supported by the Joint Weather and Climate Research Programme, a partnership between the Natural Environment Research Council (NERC) and the Met Office, under University of Reading Contract R8/H9/37. AGT held a NERC Fellowship, No. NE/H015655/1. R.C.L., G.M.M., M.S.M., M.J.R. and J.S. are supported by the Joint UK DECC/Defra Met Office Hadley Centre Climate Programme (GA01101). R.C.L., A.G.T. and G.M.M. were additionally supported by the NERC Changing Water Cycle (CWC) SAPRISE Project (reference NE/ I022841/1 and NE/I022469/1). RCL was further supported by the European Commissions 7th Framework Programme, under Grant Agreement No. 282672, EMBRACE Project. S.J.W., R.S., P.L.V., M.E.D. were supported by the National Centre for Atmospheric Science Climate directorate (NCAS-Climate), a collaborative centre of NERC. P.L.V. acknowledges the support provided to the Willis Chair in Climate System Science and Climate Hazards. While working on the UPSCALE simulations, J.S. was supported by a UK Technology Strategy Board Knowledge Transfer Partnership. We also thank the large team of model developers, infrastructure experts and all the other essential components required to conduct the UPSCALE campaign, in particular the PRACE infrastructure and the Stuttgart HLRS supercomputing centre, as well as the STFC CEDA service for data storage and analysis using the JASMIN platform. We acknowledge use of the MONSooN system, a collaborative facility supplied under the Joint Weather and Climate Research Programme, which is a strategic partnership between the Met Office and the Natural Environment Research Council. We acknowledge the use of e-Atlas products developed by Cyclone warning Research Centre, Regional Meteorological Centre, Chennai, India. GPCP Precipitation data is provided by the NOAA/OAR/ESRL PSD, Boulder, Colorado, USA, from their web site at http://www.esrl.noaa.gov/psd/.

Open Access This article is distributed under the terms of the Creative Commons Attribution 4.0 International License (http://creativecommons.org/licenses/by/4.0/), which permits unrestricted use, distribution, and reproduction in any medium, provided you give appropriate credit to the original author(s) and the source, provide a link to the Creative Commons license, and indicate if changes were made.

\section{References}

Adler RF, Huffman GJ, Chang A, Ferraro R, Xie PP, Janowiak J, Rudolf B, Schneider U, Curtis S, Bolvin D, Gruber A, Susskind J, Arkin P, Nelkin E (2003) The version-2 global precipitation climatology project (GPCP) monthly precipitation analysis (1979-present). J Clim 4:1147-1167

Annamalai H, Hamilton K, Sperber KR (2007) The South Asian summer monsoon and its relationship with ENSO in the IPCC AR4 simulations. J Clim 20(6):1071-1092. doi:10.1175/JCLI4035.1

Arakawa A, Lamb V (1977) Computational design of the basic dynamical processes of the UCLA general circulation model, vol 17. Academic Press, New York, pp 173-265
Ashok K, Soman MK, Satyan V (2000) Simulation of monsoon disturbances in a GCM. Pure Appl Geophys 157:1509-1539

Bacmeister JT, Wehner MF, Neale RB, Gettelman A, Hannay C, Lauritzen PH, Caron JM, Turesdale JE (2014) Exploratory high-resolution climate simulations using the community atmosphere model (CAM). J Clim 27:3073-3099. doi:10.1175/ JCLI-D-13-00387.1

Bengtsson L, Hodges KI, Roeckner E (2006) Storm tracks and climate change. J Clim 19:3518-3543

Best MJ, Pryor M, Clark DB, Rooney GG, Essery RLH, Menard CB, Edwards JM, Hendry MA, Porson A, Gedney N, Mercado LM, Sitch S, Blyth E, Boucher O, Cox PM, Grimmond CSB, Harding RJ (2011) The joint UK land environment simulator (JULES), model description-part 1: energy and water fluxes. Geosci Model Dev 4:677-699. doi:10.5194/gmd-4-677-2011

Bollasina M, Nigam S (2009) Indian Ocean SST, evaporation, and precipitation during the South Asian summer monsoon in IPCC-AR4 coupled simulations. Clim Dyn 33:1017-1032. doi:10.1007/s00382-008-0477-4

Boos WR, Kuang Z (2010) Dominant control of the South Asian monsoon by orographic insulation versus plateau heating. Nature 463(7278):218-222. doi:10.1038/nature08707

Boos WR, Kuang Z (2013) Sensitivity of the South Asian monsoon to elevated and non-elevated heating. Scientific Reports 3(1192):36. doi:10.1038/srep01192

Bracco A, Kucharski F, Molteni F (2005) Internal and forced modes of variability in the Indian Ocean. Geophys Res Lett 32:1-4. doi: 10.1029/2005GL023154

Brown AR, Webster S (2004) Orographic flow-blocking scheme characteristics. Q J R Meteorol Soc 130:3015-3028. doi:10.1256/ qj.04.40

Chakraborty A, Nanjundiah RS, Srinivasan J (2006) Theoretical aspects of the onset of Indian summer monsoon from perturbed orography simulations in a GCM. Ann Geophys 24(2003):2075-2089

Charney JG, Phillips NA (1953) Numerical Integration of the quasigeostrophic equations for barotropic and simple baroclinic flows. J Meteorol 10(2):71-99

Clark DB, Mercado LM, Sitch S, Jones CD, Gedney N, Best MJ, Pryor M, Rooney GG, Essery RLH, Blyth E, Boucher O, Harding RJ, Huntingford C, Cox PM (2011) The joint UK land environment simulator (JULES), model description-part 2: carbon fluxes and vegetation dynamics. Geosci Model Dev 4:701-722. doi:10.5194/gmd-4-701-2011

Davies T, Cullen MJP, Malcolm AJ, Mawson MH, Staniforth A, White AA, Wood N (2005) A new dynamical core for the Met Offices global and regional modelling of the atmosphere. Q J R Meteorol So 131:1759-1782. doi:10.1256/qj.04.101

Dee DP, Uppala SM, Simmons AJ, Berrisford P, Poli P, Kobayashi S, Andrae U, Balmaseda MA, Balsamo G, Bauer P, Bechtold P, Beljaars ACM, Berg LVD, Bidlot J, Bormann N, Delsol C, Dragani R, Fuentes M, Geer AJ, Dee DP (2011) The ERA-Interim reanalysis: configuration and performance of the data assimilation system. Q J R Meteorol Soc 137:553-597. doi:10.1002/qj.828

Delworth TL, Rosati A, Anderson W, Adcroft AJ, Balaji V, Benson R, Dixon K, Griffies SM, Lee HC, Pacanowski RC, Vecchi GA, Wittenberg AT, Zeng F, Zhang R (2012) Simulated climate and climate change in the GFDL CM2.5 high-resolution coupled climate model. J Clim 25:2755-2781. doi:10.1175/ JCLI-D-11-00316.1

Demory ME, Vidale PL, Berrisford P, Strachan J, Schiemann R, Roberts MJ, Mizielinski MS (2014) The role of horizontal resolution in simulating drivers of the global hydrological cycle. Clim Dyn 42(7-8):2201-2225. doi:10.1007/s00382-013-1924-4

Donlon CJ, Martin M, Stark J, Roberts-Jones J, Fiedler E, Wimmer W (2012) Remote sensing of environment the operational 
sea surface temperature and sea ice analysis (OSTIA) system. Remote Sens Environ 116:140-158. doi:10.1016/j. rse.2010.10.017

Fritsch JM, Chappell CF (1980a) Numerical prediction of convectively driven mesoscale pressure systems-part I: convective parameterization. J Atmos Sci 37:1722-1733

Fritsch JM, Chappell CF (1980b) Numerical prediction of convectively driven mesoscale pressure systems-part II: mesoscale model. J Atmos Sci 37:1735-1762

Gadgil S, Sajani S (1998) Monsoon precipitation in the AMIP runs. Clim Dyn 14:659-689

GLOBE Task Team (1999) The global land one-kilometer base elevation (GLOBE) digital elevation model, version 1.0. Technical report, National Oceanic and Atmospheric Administration, National Geophysical Data Center, 325 Broadway, Boulder, Colorado 80305-3328, USA. http://www.ngdc.noaa.gov/mgg/topo/ globe.html

Gregory D, Allen S (1991) The effect of convective downdrafts upon NWP and climate simulations. In: Proceedings of the ninth conference on numerical weather prediction. American Meteorological Society, Denver, Colorado, pp 122-123

Gregory D, Rowntree PR (1990) A mass flux convection scheme with representation of cloud ensemble characteristics and stability dependant closure. Mon Weather Rev 118:1483-1506

Gregory D, Shutts GJ, Mitchell JR (1998) A new gravity-wave-drag scheme incorporating anisotropic orography and low-level wave breaking: impact upon the climate of the UK Meteorological Office Unified Model. Q J R Meteorol Soc 124:463-493

Hodges KI (1994) A general method for tracking analysis and its application to meteorological data. Mon Weather Rev 122:2573-2586

Hoskins BJ, Rodwell MJ (1995) A model of the Asian summer monsoon. Part I: the global scale. J Atmos Sci 52(9):1329-1340

Huffman GJ, Adler RF, Morrissey MM, Bolvin DT, Curtis S, Joyce R, McGavok B, Susskind J (2001) Global precipitation at onedegree daily resolution from multisatellite observations. J Hydrometeorol 2:36-50

IMD (2011) IMD Cyclone and Monsoon Depression eAtlas. Technical report, cyclone warning Research Centre, Regional Meteorological Centre, Chennai, India. http://www.rmcchennaieatlas. tn.nic.in

Jha B, Krishnamurti TN, Christides Z (2000) A note on horizontal resolution dependance for monsoon rainfall simulations. Meteorol Atmos Phys 74:11-17

Johns TC, Durman CF, Banks HT, Roberts MJ, McLaren AJ, Ridley JK, Senior CA, Williams KD, Jones A, Rickard GJ, Cusack S, Ingram WJ, Crucifix M, Sexton DMH, Joshi MM, Dong BW, Spencer H, Hill RSR, Gregory JM, Keen AB, Pardaens AK, Lowe JA, Bodas-Salcedo A, Stark S, Searl Y (2006) The new hadley centre climate model (HadGEM1): evaluation of coupled simulations. J Clim 19:1327-1353

Kanji GK (2006) 100 statistical tests, 3rd edn. Sage, Beverly Hills, CA

Kim HJ, Wang B, Ding Q (2008) The global monsoon variability simulated by CMIP3 coupled climate models*. J Clim 21(20):52715294. doi:10.1175/2008JCLI2041.1

Kitoh A, Kusunoki S (2008) East Asian summer monsoon simulation by a 20-km mesh AGCM. Clim Dyn 31:389-401. doi:10.1007/ s00382-007-0285-2

Kobayashi C, Sugi M (2004) Impact of horizontal resolution on the simulation of the Asian summer monsoon and tropical cyclones in the JMA global model. Clim Dyn 93:165-176. doi:10.1007/ s00382-004-0427-8

Krishnamurthy V, Misra V (2010) Daily atmospheric variability in the South American monsoon system. Clim Dyn 37(3-4):803-819. doi:10.1007/s00382-010-0881-4
Kumar KK, Rajagopalan B, Hoerling M, Bates G, Cane M (2006) Unraveling the mystery of indian monsoon failure during $\mathrm{El}$ Nino. Science 314:115-119. doi:10.1126/science.1131152

Landu K, Leung R, Hagos S, Vinoj V (2014) The dependence of ITCZ structure on model resolution and dynamical core in aquaplanet simulations. J Clim 27:2375-2385. doi:10.1175/ JCLI-D-13-00269.1

Li C, Yanai M (1996) The onset and interannual variability of the Asian summer monsoon in relation to land-sea thermal contrast. J Clim 9:358-375

Mann HB, Whitney DR (1947) On a test of whether one of two random variables is stochastically larger than the other. Ann Math Stat 18(1):50-60

Martin GM (1999) The simulation of the Asian summer monsoon, and its sensitivity to horizontal resolution, in the UK Meteorological Office Unified Model. Q J R Meteorol Soc 125:1499-1525

Meehl GA, Covey C, Delworth T, Latif M, McAvaney B, Mitchell JFB, Stouffer RJ, Taylor KE (2007) The WCRP CMIP3 multimodel dataset. Bull Am Meteorol Soc 88:1383-1394. doi:10.1175/BAMS-88-9-1383

Mizielinski MS, Roberts MJ, Vidale PL, Schiemann R, Demory ME, Strachan J, Edwards T, Stephens A, Lawrence BN, Pritchard M, Chiu P, Iwi A, Churchill J, del Cano Novales C, Kettleborough J, Roseblade W, Selwood P, Foster M, Glover M, Malcolm A (2014) High resolution global climate modelling; the UPSCALE project, a large simulation campaign. Geosci Model Dev 7:1629_ 1640. doi:10.5194/gmdd-7-563-2014

Neale RB, Slingo J (2003) The Maritime Continent and its role in the global climate: a GCM study. J Clim 16:834-848

Randall et al (2007) Climate models and their evaluation. In: Climate change 2007: IPCC working group I: the physical science basis. Cambridge University Press, Cambridge, UK and New York, pp 590-662

Rienecker MM, Suarez MJ, Gelaro R et al (2011) MERRA: NASA s modern-era retrospective analysis for research and applications. Society 24:3624-3648. doi:10.1175/JCLI-D-11-00015.1

Risien CM, Chelton DB (2008) A global climatology of surface wind and wind stress fields from eight years of QuickSCAT scatterometer data. J Phys Oceanogr 38:2379-2413. doi:10.1175/2008 JPO3881.1

Roberts MJ, Vidale PL, Mizielinski MS, Demory ME, Schiemann R, Strachan J, Hodges K, Camp J, Bell R (2015) Tropical cyclones in the UPSCALE ensemble of high resolution global climate models. J Clim 28:574-596

Rodwell MJ, Hoskins BJ (1995) A model of the Asian summer monsoon. Part II: cross-equatorial flow and PV behavior. J Atmos Sci 52(9):1341-1356

Sabeerali CT, Dandi AR, Dhakate A, Salunke K, Mahapatra S, Rao SA (2013) Simulation of boreal summer intraseasonal oscillations in the latest CMIP5 coupled GCMs. J Geophys Res 118:4401-4420. doi:10.1002/jgrd.50403

Sabin TP, Ghattas J, Denvil S, Jl Dufresne, Hourdin F, Pascal T (2013) High resolution simulation of the South Asian monsoon using a variable resolution global climate model. Clim Dyn 41:173-194. doi:10.1007/s00382-012-1658-8

Sabre M, Hodges KI, Laval K, Polcher J, Desalmand F (2000) Simulation of monsoon disturbances in the LMD GCM. Mon Weather Rev 128:3752-3771

Schiemann R, Demory ME, Mizielinski MS, Roberts MJ, Shaffrey LC, Strachan J, Vidale PL (2014) The sensitivity of the tropical circulation and Maritime Continent precipitation to climate model resolution. Clim Dyn 42:2455-2468. doi:10.1007/ s00382-013-1997-0

Shin DW, Larow TE, Cocke S (2003) Convective scheme and resolution impacts on seasonal precipitation forecasts. Geophys Res Lett 30(20):2078. doi:10.1029/2003GL018297 
Sikka DR (1977) Some aspects of the life history, structure and movement of monsoon depressions. Pure Appl Geophys 115:1501-1529

Slingo J, Spencer H, Hoskins B, Berrisford P, Black E (2005) The meteorology of the Western Indian Ocean, and the influence of the East African highlands. Philos Trans R Soc 363:25-42. doi:10.1098/rsta.2004.1473

Sperber KR, Palmer TN (1996) Interannual tropical rainfall variability in general circulation model simulations associated with the atmospheric model intercomparison project. J Clim 9:2727-2750

Sperber KR, Hameed S, Potter GL, Boyle JS (1994) Simulation of the northern summer monsoon in the ECMWF model: sensitivity to horizontal resolution. J Clim 122:2461-2841

Sperber KR, Annamalai H, Kang IS, Kitoh A, Moise A, Turner AG, Wang B, Zhou T (2013) The Asian summer monsoon: an intercomparison of CMIP5 vs. CMIP3 simulations of the late 20th century. Clim Dyn 41:2711-2744. doi:10.1007/s00382-012-1607-6

Stephenson DB, Chauvin F, Royer JF (1998) Simulation of the Asian summer monsoon and its dependence on model horizontal resolution. J Meteorol Soc Jpn 76(2):237-265

Stowasser M, Annamalai H, Hafner J (2009) Response of the South Asian summer monsoon to global warming: mean and synoptic systems. J Clim 22:1014-1036. doi:10.1175/2008JCLI2218.1

Strachan J (2007) Understanding and modelling the climate of the Maritime Continent. Ph.D. thesis, University of Reading

Strachan J, Vidale PL, Hodges KI, Roberts MJ, Demory ME (2013) Investigating global tropical cyclone activity with a hierarchy of AGCMs: the role of model resolution. J Clim 26:133-152. doi:10.1175/JCLI-D-12-00012.1

Stratton RA, Stirling A, Derbyshire S (2009) Changes and developments to convective momentum transport (CMT) parameterization based on analysis of CRM and SCM: Technical note 530. Technical report 530, UK Met Office

Tang H, Micheels A, Eronen JT, Ahrens B, Fortelius M (2013) Asynchronous responses of East Asian and Indian summer monsoons to mountain uplift shown by regional climate modelling experiments. Clim Dyn 40:1531-1549. doi:10.1007/s00382-012-1603-x

Taylor KE, Stouffer RJ, Meehl GA (2012) An overview of CMIP5 and the experiment design. Bull Am Meteorol Soc 93:485-498. doi:10.1175/BAMS-D-11-00094.1

Turner AG, Martin GM, Levine RC (2015) The role of peninsular India in the South Asian summer monsoon. Clim Dyn (submitted)

US Department of Commerce (2001) 2-Minute gridded global relief data (ETOPO2). Technical report, National Oceanic and Atmospheric Administration

Walters DN, Best MJ, Bushell AC, Copsey D, Edwards JM, Falloon PD, Harris CM, Lock AP, Manners JC, Morcrette CJ, Roberts
MJ, Stratton RA, Webster S, Wilkinson JM, Willett MR, Boutle IA, Earnshaw PD, Hill PG, Maclachlan C, Martin GM, Palmer MD, Petch JC, Rooney GG, Scaife AA, Williams KD (2011) The Met Office Unified Model global atmosphere 3.0/3.1 and JULES global land 3.0/3.1 configurations. Geosci Model Dev 4:919941. doi:10.5194/gmd-4-919-2011

Walters DN, Williams KD, Boutle IA, Bushell AC, Edwards JM, Field PR, Lock AP, Morcrette CJ, Stratton RA, Wilkinson JM, Willett MR, Brooks ME, Copsey D, Earnshaw PD, Harris CM, Manners JC, MacLachlan C, Palmer MD, Roberts MJ, Tennant WJ (2015) The Met Office Unified Model global atmosphere 6.0/6.1 and JULES Global Land 6.0/6.1.0 congurations. In preparation

Wang B, Jy Lee, Kang IS, Shukla J, Kug JS, Kumar JS, Schemm J, Luo KJ, Yamagata T, Park CK (2008) How accurately do coupled climate models predict the leading modes of Asian-Australian monsoon interannual variability? Clim Dyn 30:605-619. doi:10.1007/s00382-007-0310-5

Webster PJ, Yang S (1992) Monsoon and ENSO: selectively interactive systems. Q J R Meteorol So 118:877-926

Williamson DL (2008) Convergence of aqua-planet simulations with increasing resolution in the Community Atmospheric Model, Version 3. Tellus 60A:848-862. doi:10.1111/j.1600-0870.2008.00339.x

Xie P, Arkin PA (1997) Global precipitation: a 17-year monthly analysis based on gauge observations, satellite estimates, and numerical model outputs. Bull Am Meteorol Soc 78(11):2539-2558

Xie SP, Xu H, Saji NH, Wang Y (2006) Role of narrow mountains in large-scale organization of Asian monsoon convection. J Clim 3420:3420-3429

Yang GY, Slingo J (2001) The diurnal cycle in the tropics. Mon Weather Rev 129(1994):784-801

Yatagai A, Arakawa O, Kamiguchi K, Kawamoto H, Nodzu MI, Hamada A (2009) A 44-year daily gridded precipitation dataset for Asia based on a dense network of rain gauges. Sci Online Lett Atmos 5:137-250. doi:10.2151/sola.2009

Yu L (2007) Global variations in oceanic evaporation (1958-2005): the role of the changing wind speed. J Clim 20:5376-5390. doi: 1 $0.1175 / 2007$ JCLI1714.1

Yu L, Jin X, Weller RA (2008) Multidecade global flux datasets from the objectively analyzed air-sea fluxes (OAFlux) project: latent and sensible heat fluxes, ocean evaporation, and related surface meteorological variables-OAFlux project technical report (OA2008-01). Technical report, January, Woods Hold Oceanographic Institution, Woods Hole, Massachusetts

Zarzycki CM, Levy MN, Jablonowski C, Overfelt J, Taylor M, Ullrich P (2014) Aquaplanet experiments using CAM's variableresolution dynamical core. J Clim 27:5481-5503. doi:10.1175/ JCLI-D-14-00004.1 